\title{
La imagen de la lagartija en la iconografía prehispánica del Noroeste Argentino I: una propuesta tipológica
}

\section{Lizard images depicted in prehispanic iconography of Northwest Argentina I: a typological proposal}

\author{
Débora M. Kligmann ${ }^{1,2}$, María Pía Falchi ${ }^{3}$
}

\section{Resumen}

El análisis de la iconografía prehispánica del Noroeste Argentino ha estado centrado principalmente en las figuras de camélidos, felinos, serpentiformes y antropomorfos. El presente trabajo busca analizar la representación de un animal escaso en el repertorio iconográfico, y en consecuencia muy poco estudiado, como es la lagartija. El objetivo es elaborar una tipología que permita, en una segunda instancia, identificar patrones en su modo de representación a lo largo del tiempo.

Para alcanzar este objetivo se recopilaron imágenes publicadas en la literatura arqueológica argentina. Asimismo, se analizaron piezas seleccionadas del Museo Nacional del Hombre y del Museo Etnográfico J.B. Ambrosetti. Todas las representaciones se clasificaron teniendo en cuenta sus características generales, así como las características morfológicas de las cabezas, los cuerpos, las patas y las colas, considerando los atributos biológicos de estos animales.

A partir de la variabilidad observada se elaboró una propuesta tipológica para el análisis de las representaciones de lagartijas. Esto permitió ordenar la información recabada y generar una herramienta metodológica. A lo largo del trabajo se discute la utilidad y alcance de este tipo de propuestas en arqueología.

Palabras claves: lagartijas, iconografía, tipología, Noroeste Argentino.

\begin{abstract}
The analysis of Northwest Argentine Prehispanic iconography has been principally centered on images of camelids, felines, serpent-like animals, and anthropomorphs. This paper seeks to analyze the representation of a scarcely depicted and consequently little studied animal, that of the lizard. In this, our aim is to provide a typology that will enable us - in the near future to identify patterns in the manner these creatures are represented across time.

In this undertaking, we compiled a catalog of lizard images from the Argentine archaeological literature. Selected pieces from the Museo Nacional del Hombre and the Museo Etnográfico J.B. Ambrosetti were also considered. In turn, all of these images were classified in respect of their general characteristics, as well as according to the morphological characteristics of their heads, bodies, legs, and tails, as informed by the biological attributes of said reptiles. Based on the variability observed, a typological approach for the analysis of lizard representations was created. This allowed us to arrange the information collected, thereby providing us with a usable methodological tool. Throughout the article, we also discuss the usefulness and scope of these types of approaches in archaeology.
\end{abstract}

Keywords: lizards, iconography, typology, Northwest Argentina.

Recibido: 28 febrero 2017. Aceptado: 16 noviembre 2017

1 CONICET. Buenos Aires, ARGENTINA. Email: kligmann@gmail.com

2 Instituto de Arqueología, Facultad de Filosofía y Letras, Universidad de Buenos Aires. Buenos Aires, ARGENTINA. Email: kligmann@gmail.com

3 Instituto Nacional de Antropología y Pensamiento Latinoamericano, Ministerio de Cultura de la Nación. Buenos Aires, ARGENTINA. Email: mariapia.falchi@inapl.gob.ar 


\section{Introducción}

El trabajo que aquí se presenta se inserta en un proyecto de mayor alcance, cuyo objetivo general es establecer cambios en el modo de representación de los reptiles a lo largo del tiempo en el Noroeste Argentino (NOA) (Kligmann y Díaz País, 2007). Para ello se deben buscar los patrones compositivos por período, tomando en cuenta tanto lagartijas como serpentiformes. Esto permitirá comprender las características de los distintos tipos de reptiles para luego identificar semejanzas y diferencias entre ellos.

Los reptiles son muy frecuentes en la iconografía prehispánica del NOA. Las representaciones de estos animales comienzan a registrarse durante el período Formativo, continúan en el período de Integración Regional, alcanzan su máxima popularidad durante el período de Desarrollos Regionales y disminuyen en el período Inca (Kligmann y Díaz País, 2007).

Los motivos de reptiles están plasmados en una gran variedad de soportes, incluyendo cerámica, roca (arte rupestre y mobiliar), metal, hueso, madera, calabaza y fibra vegetal. Para realizarlos se emplearon diversas técnicas tales como modelado, pintado, grabado, tejido y bordado (Kligmann y Díaz País, 2007).

Ahora bien, a pesar de la gran cantidad de reptiles presentes en la iconografía, los hallazgos de restos faunísticos de estos animales en sitios arqueológicos de la Argentina son escasos. De los 25 casos que conocemos, de los cuales cinco provienen del NOA, solo dos corresponden a grandes acumulaciones (más de 1700 especímenes) de pequeños reptiles, y ambas fueron recuperadas en sitios de esta región: lagartijas (Albino y Kligmann, 2007; Kligmann, 2009, 2015; Kligmann, Sesé y Barbadillo, 1999) y anfisbenas (Albino y Kligmann, 2009; Kligmann, 2015; Kligmann y Albino, 2007; Kligmann, Albino y Díaz País, 2013). Los 23 casos restantes dan cuenta de unos pocos individuos aislados, identificados como lagartos, serpientes y tortugas (Kligmann, 2009, 2015; Kligmann y Díaz País, 2007; Kligmann et al., 2013).

El presente trabajo busca analizar la representación de un animal escaso en el repertorio prehispánico y, por ende, muy poco estudiado en la iconografía del
NOA, cuyo análisis ha estado centrado principalmente en las figuras de camélidos, felinos, serpentiformes y antropomorfos. El objetivo es elaborar una tipología que permita, en una segunda instancia, identificar patrones en el modo de representación de las lagartijas. De esta manera se podrá discutir su imagen en la iconografía prehispánica del NOA, teniendo en cuenta los diferentes períodos y soportes.

Este análisis se basa en el conocimiento previo de reptiles en general (restos óseos) y de la representación de estos animales (registro iconográfico) (Albino y Kligmann, 2007, 2009; Kligmann et al., 1999, 2013; Kligmann, 2009, 2015; Kligmann y Albino, 2007; Kligmann y Díaz País, 2007, entre otros), así como en el conocimiento de iconografía del NOA y Cuyo y en la elaboración de propuestas tipológicas previas (Falchi y Podestá, 2015; Falchi, Podestá, Rolandi, Ré y Torres, 2011; Falchi, Podestá, Rolandi y Torres, 2013; Podestá y Falchi, 2015, entre otros).

Cabe aclarar que la palabra 'lagartija' no es un término biológico sino un nombre común que engloba un grupo de saurios diversos de características variadas, en general de tamaño pequeño, en contraposición a los lagartos (Adriana Albino, com. pers.). No obstante, en las representaciones analizadas para este trabajo, ambos -lagartos y lagartijas- pueden confundirse, especialmente teniendo en cuenta que muchas de estas representaciones no proveen información sobre el tamaño real de los animales.

\section{Acerca de las clasificaciones y las tipologías en arqueología}

\section{¿Qué es una tipología? ¿Qué es un tipo?}

Una tipología consiste en el ordenamiento sistemático o clasificación de los restos materiales en grupos, clases o tipos a partir de características comunes compartidas o atributos. Una de las tareas del arqueólogo es simplificar los datos con el objetivo de revelar patrones significativos, organizando la variabilidad de los artefactos recuperados en unidades manejables. Describir objeto por objeto cuando todos tienen atributos compartidos o elementos en común (salvo que se trate de un hallazgo único) carece de utilidad. El sentido está en los patrones que pueda 
haber en los datos y en lo que éstos puedan explicar sobre las sociedades del pasado, no en los datos en sí mismos. A partir de los resultados obtenidos se pueden discutir cuestiones espaciales, temporales, económicas o ideológicas (Balme y Paterson, 2006; Banning, 2000; Renfrew y Bahn, 1991; Rice, 1997; Sharer y Ashmore, 1987; Thomas y Kelly, 2006).

Algunos atributos se expresan de manera cualitativa (p.e., presencia / ausencia) y otros, cuantitativa (p.e., largo, ancho y espesor). Cada atributo tiene dos (p.e., presencia / ausencia) o más posibilidades (p.e., color, tamańo, forma) (Sharer y Ashmore, 1987; Thomas y Kelly, 2006).

La clasificación es el proceso de separar datos en tipos discretos. Los tipos son combinaciones de características (atributos) que permiten distinguir un objeto de otro. Son la unidad básica de clasificación (Banning, 2000; Fagan, 2003). Un mismo objeto puede ser clasificado de muchas formas diferentes. Los tipos son abstracciones creadas por el investigador, ya que no hay nada inherente a un artefacto que lo haga pertenecer a una u otra categoría (Thomas y Kelly, 2006).

Las clasificaciones imponen límites rígidos a restos que pueden formar un continuum (Balme y Paterson, 2006). Una de las características de las clasificaciones es que son completamente arbitrarias. Si bien existen buenas razones para organizar los datos de maneras particulares, hay infinitas posibilidades de reorganizar y agrupar los datos. Para ello resultan fundamentales las preguntas arqueológicas que guían la investigación (Banning, 2000).

\section{Características de una buena tipología}

Las tipologías dependen de las preguntas de investigación y de la naturaleza de los datos que están siendo analizados, ya que no hay dos colecciones iguales (Balme y Paterson, 2006; Rice, 1997; Sharer y Ashmore, 1987; Thomas, 1979; Thomas y Kelly, 2006). Todas tienen un propósito y todas son válidas. No hay clasificaciones generales multipropósito (Thomas y Kelly, 2006), por lo que frente a diferentes preguntas son necesarias diferentes clasificaciones. Las clasificaciones deberían ser un medio para un fin y no un fin en sí mismo (Renfrew y Bahn, 1991).
Las tipologías exitosas deben dar cuenta de toda la variabilidad observada. Muchas clasificaciones fallan porque comprenden una categoría de 'misceláneos' en la cual se incluyen los datos que no pueden ser incorporados en ninguna de las categorías existentes en lugar de revisar la clasificación para incluir los objetos únicos (Balme y Paterson, 2006).

Las dos características de una buena tipología son (Balme y Paterson, 2006; Banning, 2000; Thomas y Kelly, 2006):

1. Debe minimizar las diferencias entre cada tipo creado y maximizar aquellas entre los distintos tipos. Si hay ambigüedad y superposición en los tipos, no van a resultar de utilidad para revelar ningún patrón significativo. Así, las clases deben ser mutuamente excluyentes. Es preferible crear pocas categorías con varios ítems cada una, en lugar de numerosas clases vacías. Para ello es necesario tomar en cuenta diversos atributos y generar muchas categorías y ponerlas a prueba con los datos reales. Esto se debe a que se trata de un proceso dinámico que se va ajustando a medida que se cruza la tipología con los datos y se van agregando nuevos casos.

2. Debe ser objetiva y explícita. Esto significa que el resultado debe ser replicable por cualquier observador entrenado. La ambigüedad de las clasificaciones se puede reducir siendo muy explícitos acerca de las categorías elegidas y sus límites.

\section{Tipos de tipologías y tipos de tipos}

Hay tipologías y tipos descriptivos o morfológicos, cronológicos, funcionales y estilísticos (Fagan, 2003; Renfrew y Bahn, 1991; Rice, 1997; Sharer y Ashmore, 1987; Thomas y Kelly, 2006). Las tipologías de distinto tipo no necesariamente se corresponden (p.e., morfológicas y funcionales, lo que significa que objetos con la misma forma se pueden haber utilizado para cumplir funciones diferentes).

Al clasificar los artefactos en tipos y evaluar sus cambios a través del tiempo, los arqueólogos han desarrollado una serie de esquemas cronológicos que han ayudado a ordenar el registro arqueológico. Estos tipos constituyen herramientas válidas para explorar 
el pasado que reflejan el modo en que se ven los artefactos actualmente más que como los veían los artesanos que los elaboraron o usaron (Staeck, 2002; Thomas y Kelly, 2006). Por lo tanto, no es posible garantizar que las categorías establecidas por los investigadores hayan tenido algún significado para las sociedades del pasado y que fueran reconocidas como tales (Staeck, 2002).

En la década de 1950 surgió una discusión en la literatura arqueológica acerca del significado de las tipologías, con dos posturas contrapuestas. Una proponía que las clasificaciones o agrupaciones eran naturales (Spaulding, 1953), mientras que la otra planteaba que eran artificiales (Ford, 1954). Para la primera, la clasificación no sería un procedimiento arbitrario, sino que los tipos existirían como combinaciones de atributos que son elegidos o creados por quien manufactura los objetos. La herramienta para descubrir estos tipos es la estadística. Para la segunda, los investigadores imponen una clasificación dependiendo de sus preguntas de investigación. Los tipos reales no existen en la cultura que manufactura los objetos en cuestión. Los tipos constituyen maneras artificiales de clasificar objetos y permiten apreciar el grado de variabilidad de la cultura material para un grupo artefactual. Dicho de otro modo, esta polémica clásica se debatía entre dos posturas: una etic, en donde las categorías son construidas por observantes externos, y otra emic, que toma en cuenta las categorías que los informantes del pasado aceptarían como verdaderas o válidas (Staeck, 2002).

Independientemente de la tipología que se utilice para clasificar, agrupar y ordenar los restos materiales estudiados, es obvio que la manera de hacerlo de los arqueólogos no necesariamente coincide con la de los autores de las representaciones, si es que clasificaban su propio trabajo. Por lo tanto, todas las clasificaciones son subjetivas y sirven al solo efecto de analizar los restos arqueológicos en la actualidad (Rice, 1997).

\section{¿Para qué se han utilizado las tipologías en arqueología?}

En algunos casos las tipologías se han utilizado para elaborar secuencias temporales o cronológicas, ya que determinados tipos se corresponden con ciertos momentos. Esto se basa en la idea de que los restos producidos en un determinado momento y lugar tienen un estilo característico y están vinculados con la sociedad que los produjo. Otro presupuesto subyacente de esta afirmación es que los productos elaborados en un mismo momento tienden a ser parecidos, mientras que aquellos creados con varios siglos de diferencia, a ser distintos, como resultado de cientos o incluso miles de años de cambio (Renfrew y Bahn, 1991; Rice, 1997). Esta posición ha sido superada y en este trabajo no se pretende hacer una tipología de esta índole.

\section{Las tipologías y la iconografía}

Hasta aquí se han discutido las características de las tipologías de artefactos arqueológicos, especialmente cerámicos y líticos, las cuales son mucho más abundantes que las clasificaciones de imágenes. No obstante nuestra propuesta construye una tipología de representaciones (no artefactos en sentido material), las cuales tienen un modo particular de ser usadas. Estos conceptos se relacionan con la definición de estilo. Se entiende el estilo como los modos de hacer y usar lo material, basados en patrones y estructuras aprendidos socialmente en un determinado tiempo y lugar (Conkey y Hastorf, 1990). De la misma manera, el modo de representación está íntimamente ligado a las prácticas sociales pero no de una manera unívoca y estática sino, por el contrario, como herramienta para dar sentido al mundo y como espacio de negociación social.

En consecuencia, es importante conocer los patrones de representación de determinados elementos a lo largo del tiempo con el objetivo de comprender las características de los cambios sociales que pueden estar reflejando (Valenzuela, Sepúlveda, Santoro y Montt, 2014; Troncoso, 2003). Esta propuesta se basa en ordenar la información en forma de tipologías para detectar dichos cambios.

Como antecedente de propuestas tipológicas o clasificatorias en Argentina para iconografía -tanto rupestre como mobiliar-, se pueden mencionar valiosos aportes (Aschero, 2000; Basile y Buono, 2013; Gordillo, Baldini y Kusch, 2000; Kusch, 1991; Montenegro y Ruiz, 2004; Podestá, Ré y Romero Villanueva, 2001 y Romero, 2016, entre otros). 


\section{Definiendo el universo a analizar}

El orden Squamata (reptiles cuyos cuerpos están cubiertos de escamas) incluye lacertilios o saurios (lagartijas, lagartos, iguanas, camaleones y geckos, entre otros), serpientes y anfisbenas (Garín y Hussein, 2013; Palermo, 1984b).

Tanto lagartija como lagarto son nombres comunes que se les da a una gran cantidad y variedad de lacertilios. Son términos muy amplios, pero en general se interpreta que un lagarto es más grande que una lagartija y que dentro de los lagartos puede haber formas sin patas o con patas reducidas, mientras que las lagartijas siempre tienen cuatro patas. De todos modos, dentro de este universo la biología distingue categorías que no se definen solamente por el tamańo del saurio, sino por otras características más o menos perceptibles (Adriana Albino, com. pers.), que incluyen desde el estudio cromosómico hasta el de su estructura ósea (Palermo, 1984a).

Lagartos y lagartijas constituyen por lo tanto un grupo muy variado y heterogéneo, con diferencias que abarcan desde sus hábitos alimentarios (hay especies carnívoras, herbívoras y omnívoras) hasta los hábitats donde viven (existen especies adaptadas a zonas tropicales y templadas y otras que habitan regiones cercanas a los círculos polares, así como en diferentes altitudes). Asimismo se observan diferencias en sus dimensiones; la coloración de sus cuerpos; el tamaño, forma y disposición de las escamas que los recubren; sus formas de reproducción (la mayoría son ovíparos, pero existen formas vivíparas, que incuban los huevos dentro de sus cuerpos y luego paren crías vivas); la cantidad de individuos por parición y las formas y dimensiones de las partes de sus cuerpos (incluyendo cabezas, lenguas y colas) (Garín y Hussein, 2013; Palermo, 1984a).

Poseen la habilidad de desprenderse de sus colas en momentos de peligro, hecho denominado autotomía, las cuales se regeneran aunque usualmente resultan más cortas que las originales, pudiendo crecer bifurcadas (Palermo, 1984a).

Si bien existen reptiles bicéfalos, estas situaciones son excepcionales en la naturaleza, siendo más fre- cuentes entre las serpientes que entre los saurios. Se trata de una anomalía genética que produce individuos que comparten partes del cuerpo y por ende sus órganos. Debido a esta malformación embrionaria los animales no suelen sobrevivir por mucho tiempo. Las víboras con una cabeza en cada extremo del cuerpo, tal como se ilustran en el arte precolombino, no existen en la realidad. Excepcionalmente, algunas víboras nacen con dos cabezas ubicadas una al lado de la otra en un mismo extremo del cuerpo (Kligmann et al., 2013). En el caso de las lagartijas, ambas cabezas pueden estar una al lado de la otra o bien una en cada extremo del cuerpo, al igual que sucede con las tortugas. Así, las representaciones bicéfalas podrían estar reflejando dichas anomalías o bien ser interpretaciones de la realidad de seres reales o míticos, con o sin connotaciones simbólicas.

A pesar de la variabilidad recién mencionada, las lagartijas comparten ciertas características básicas: a) cabeza triangular o terminada en punta; b) cuerpo alargado (más largo que ancho); c) cuatro patas desarrolladas en forma perpendicular al cuerpo (en todos los reptiles con patas éstas se sitúan perpendiculares al cuerpo y, a su vez, los huesos distales perpendiculares a los proximales de modo tal que la parte ventral del animal quede cerca del suelo, favoreciendo el reptaje); d) cinco dedos en cada pata y e) cola larga (más larga que las patas traseras). Cabe destacar que ningún reptil tiene orejas (Adriana Albino, com. pers.).

La asignación familiar, o eventualmente genérica o específica, de las representaciones de lagartijas se realiza a partir de ciertos atributos que es necesario discutir: ¿qué características tienen que tener para ser consideradas como tales?, ¿el hecho de que tengan cola las define como lagartijas?, ¿depende del largo de las colas?, ¿hay casos con 'colas' que pueden considerarse como antropomorfos masculinos?, ¿si no tienen cola no son lagartijas?

A lo largo del análisis se encontraron figuras con un apéndice que podrían corresponder a más de un grupo animal por carecer de elementos morfológicos diagnósticos. Dependiendo del autor que se consulte, las figuras en cuestión pueden ser descriptas como antropomorfos o lagartijas, sin fundamentar su asignación. En el primer caso, se interpreta 
dicho apéndice como un indicador de sexo masculino, mientras que en el segundo ese mismo apéndice se interpreta como una cola larga. En este análisis se optó por la siguiente definición: se lo considera antropomorfo cuando el apéndice es de igual o menor largo que las patas traseras, mientras que se la considera lagartija cuando su largo es mayor que el largo de las patas traseras.

En función de todo lo antedicho, en el presente trabajo se decidió que las representaciones de lagartijas, para ser consideradas como tales, debían cumplir con al menos tres de las cinco características básicas anteriormente mencionadas.

El contexto resultó fundamental a la hora de interpretar algunas de las imágenes recopiladas. Por ejemplo, se encontró un caso de varias representaciones en un mismo soporte, en donde una sola de ellas era diferente al resto, dificultando su caracterización. Sin embargo, por extensión, se decidió que correspondía al mismo grupo animal que las representaciones restantes ya que compartía varios atributos. Otro caso lo constituye el animal representado en una pieza incaica (un plato pato) que posee las mismas características que los ejemplos del Tardío pero solo tiene dos patas. Por lo tanto, siguiendo el criterio antes mencionado, se lo consideró como una lagartija.

Las figuras de posibles lagartijas que resultaban dudosas porque estaban incompletas o porque presentaban atributos poco claros no fueron tomadas en cuenta para el presente trabajo.

\section{Metodología}

Para la elaboración del presente trabajo se tomó como modelo el análisis de las representaciones de serpentiformes adscriptos a la cultura Aguada, realizado previamente por una de nosotras (Kligmann y Díaz País, 2007), pero teniendo en cuenta las particularidades de las lagartijas (p.e., presencia de cola y patas, ausentes en los serpentiformes).

El análisis aquí presentado se dividió en dos etapas. La primera consistió en la recopilación y digitaliza- ción (escaneado y calcado) de imágenes de lagartijas presentes en la iconografía prehispánica del NOA. En la segunda etapa se clasificaron dichas imágenes y se relevaron patrones en el modo de representación de las lagartijas a fin de elaborar una tipología. Por lo tanto, el trabajo realizado se puede considerar preiconográfico (sensu Panofsky, 1988) porque se mantiene dentro del mundo de los motivos, no profundizando en su interpretación.

Para los fines de este estudio se considera el motivo o figura como unidad de análisis, concebido como unidad de ejecución y de expresión estilística. Por su parte, las representaciones son todas las manifestaciones ejecutadas en las artes plásticas y designan unidades de observación que permiten establecer asociaciones para identificar motivos. Así, motivos con diseños semejantes permiten definir grupos tipológicos, mientras que constelaciones de rasgos semejantes entre motivos permiten establecer tipos (Aschero, 1988).

\section{Materiales}

El banco de datos utilizado está compuesto por imágenes publicadas en la literatura arqueológica argentina, así como por motivos representados en piezas cerámicas -depositadas en el Museo Nacional del Hombre del Instituto Nacional de Antropología y Pensamiento Latinoamericano (INAPL)- y de metal -del Museo Etnográfico Juan Bautista Ambrosetti (FFyL, UBA)-.

Cabe aclarar que en el caso de las figuras publicadas, se consideraron las imágenes que para nosotras representaban lagartijas, independientemente de la adscripción faunística otorgada por los autores de los trabajos consultados (ver la sección anterior de este trabajo: Definiendo el Universo a Analizar). Asimismo, se asumió que dichas imágenes (tanto fotografías como dibujos) constituían reproducciones confiables de los materiales originales.

Cada representación se consideró solo una vez aunque hubiera sido publicada varias veces (ya sea por un mismo autor o por autores diferentes), para evitar redundancias en el análisis de las imágenes. 
Si bien la búsqueda fue exhaustiva, las 62 imágenes recopiladas (Tabla 1) representan solo algunos ejemplos de un conjunto mucho mayor. Hay varias figuras publicadas que seguramente quedaron fuera del alcance de esta investigación y, a su vez, hay muchas que aún se encuentran inéditas. En consecuencia, este trabajo constituye una primera aproximación a la problemática planteada, y los enunciados propuestos deberán testearse incorporando más bibliografía así como materiales de colecciones que aún no están publicados.

Cuando las imágenes originales presentaban más de una representación de lagartija, cada una fue considerada por separado (recurriendo a las letras para los motivos -a, b, c, d, etc.-, pero conservando el mismo número de figura general). Por esta razón, algunas de las figuras originales se subdividieron en unidades menores para el análisis, dando un total de 119 representaciones (Tabla 2 ).

En el conjunto analizado, para los cuatro casos de lagartijas bicéfalas se describió cada cabeza por separado para registrar eventuales diferencias entre ellas, pero considerando el motivo como una unidad.
Una vez escaneadas las figuras, solo se calcaron los motivos lagartiformes para evitar 'ruidos' como pueden ser el tamaño de las imágenes (a veces muy pequeño) o la presencia de otros elementos del campo decorativo que dificultaban su reconocimiento. Así, la digitalización de las imágenes permitió ver detalles que en las publicaciones no estaban claros.

Se decidió incluir casos conflictivos para poner a prueba la tipología, por ejemplo representaciones que combinaban atributos de más de una especie o que presentaban un solo cuerpo con dos cabezas en un mismo motivo.

El hecho de recurrir mayormente a imágenes publicadas y en menor medida a las piezas originales en sí mismas tiene sus limitaciones. En algunos casos se desconoce la posición de la imagen en la pieza real, su tamaño o con qué otras representaciones está asociada. En otros tampoco se sabe de qué tipo de pieza proviene (por ejemplo en piezas cerámicas, si se trata de un puco, una vasija, etc.). Por último, si bien se considera que la articulación espacial es una variable fundamental para comprender la relación de las distintas unidades decorativas de un mismo soporte,

Tabla 1. Cuantificación de las imágenes de lagartijas del banco de datos por soporte y período.

\begin{tabular}{|c|c|c|c|c|c|c|}
\hline \multirow{3}{*}{ Período } & \multicolumn{5}{|c|}{ Soporte } & \multirow{3}{*}{ Subtotal } \\
\hline & \multirow{2}{*}{ Cerámica } & \multicolumn{2}{|c|}{ Roca } & \multirow{2}{*}{ Metal } & \multirow{2}{*}{ Hueso } & \\
\hline & & Arte rupestre & Arte mobiliar & & & \\
\hline $\begin{array}{l}\text { Formativo } \\
\text { (500 a.C. }-650 \text { d.C.) }\end{array}$ & 4 & 1 & 1 & 0 & 0 & 6 \\
\hline $\begin{array}{l}\text { Integración Regional } \\
\text { (650 - } 850 \text { d.C.) }\end{array}$ & 21 & 5 & 0 & 0 & 1 & 27 \\
\hline $\begin{array}{l}\text { Desarrollos Regionales } \\
\text { ( } 850 \text { - } 1480 \text { d.C.) }\end{array}$ & 14 & 4 & 0 & 8 & 0 & 26 \\
\hline Inca (1480 - 1540 d.C.) & 1 & 0 & 0 & 0 & 0 & 1 \\
\hline No asignado & 2 & 0 & 0 & 0 & 0 & 2 \\
\hline Subtotal & 42 & 10 & 1 & 8 & 1 & 62 \\
\hline
\end{tabular}


Tabla 2. Cuantificación de las representaciones de lagartijas del banco de datos por soporte y período.

\begin{tabular}{|c|c|c|c|c|c|c|}
\hline \multirow{3}{*}{ Período } & \multicolumn{5}{|c|}{ Soporte } & \multirow{3}{*}{ Subtotal } \\
\hline & \multirow{2}{*}{ Cerámica } & \multicolumn{2}{|c|}{ Roca } & \multirow{2}{*}{ Metal } & \multirow{2}{*}{ Hueso } & \\
\hline & & Arte rupestre & Arte mobiliar & & & \\
\hline $\begin{array}{l}\text { Formativo } \\
\text { (500 a.C. }-650 \text { d.C.) }\end{array}$ & 12 & 1 & 1 & 0 & 0 & 14 \\
\hline $\begin{array}{l}\text { Integración Regional } \\
(650 \text { - } 850 \text { d.C.) }\end{array}$ & 36 & 15 & 0 & 0 & 1 & 52 \\
\hline $\begin{array}{l}\text { Desarrollos Regionales } \\
\text { (850 - } 1480 \text { d.C.) }\end{array}$ & 24 & 6 & 0 & 16 & 0 & 46 \\
\hline Inca (1480 - 1540 d.C.) & 1 & 0 & 0 & 0 & 0 & 1 \\
\hline No asignado & 6 & 0 & 0 & 0 & 0 & 6 \\
\hline Subtotal & 79 & 22 & 1 & 16 & 1 & 119 \\
\hline
\end{tabular}

en la mayoría de los casos no pudo ser utilizada por falta de información.

\section{Métodos}

Primero se elaboró una base de datos con información general de las figuras consideradas (período, provincia, estilo, soporte y tipo de pieza) para luego analizar detalladamente cada representación en particular.

Para el análisis propiamente dicho se tomaron en cuenta las siguientes variables:

1) Características generales: Vista y Tipo de unión (entre cabeza y cuerpo, entre cuerpo y patas y entre cuerpo y cola).

2) Características de las cabezas: Contorno + Forma, Atributos, Tipo de tratamiento y Diseños internos.

3) Caracteristicas de los cuerpos: Contorno + Forma, Tipo de tratamiento y Diseńos internos.
4) Características de las patas: Posición + Orientación, Terminación (Dedos: Forma), Tipo de tratamiento y Diseños internos.

5) Características de las colas: Forma, Terminación, Tipo de tratamiento y Diseńos internos.

A partir de la variabilidad observada se elaboró una propuesta tipológica para el análisis de las representaciones de lagartijas, siguiendo criterios establecidos en trabajos anteriores (Falchi y Podestá, 2015; Falchi et al., 2011, 2013; Kligmann y Díaz País, 2007). La creación de la tipología fue el resultado de un largo proceso de retroalimentación entre la unidad de análisis seleccionada (cada motivo) y los atributos de las variables consideradas, enfrentando el desafío de dar cuenta de todos los tipos registrados. Esto permitió ordenar la información recabada y generar una herramienta metodológica de análisis.

Para la opción planta / perfil de la vista se consideraron dos alternativas: 
1) Cuerpo en planta y cabeza de perfil, con un solo ojo y boca.

2) Cuerpo en planta y cabeza en planta, con dos ojos y boca (ya sea abierta o cerrada) que simula estar de perfil.

Para los atributos de la cabeza (ojos, boca, lengua, dientes y cuello) se registró su presencia o ausencia sin especificar el tipo o su descripción. El resto de los atributos se clasificaron de acuerdo con las opciones seleccionadas para cada una de las variables.

La categoría 'Combinado' se utilizó para figuras que presentaban varias opciones individuales vinculadas en una misma representación (p.e., motivos que incluyeran en sus diseńos internos puntos y reticulado o dedos de distinto tipo en cada una de las patas). En este caso se registró la información para las distintas opciones en una columna de observaciones, de manera tal de analizar, en una segunda instancia, si se repetían los motivos ya consignados o si aparecían alternativas nuevas.

La opción 'No corresponde' se empleó en el caso de figuras que no presentaran diseńos internos, dedos o colas. La categoría 'No determinado/a' se estableció para aquellos motivos que presentaran partes faltantes o poco claras por deterioro.

En el caso de las variables Tipo de tratamiento y Diseños internos, si bien se registraron por separado para cada parte del cuerpo, en las figuras de la tipología se presentan de manera conjunta para todo el cuerpo, para evitar duplicaciones innecesarias dado que muchas de las opciones se repetían en más de una parte de la representación.

En las 11 figuras tipológicas realizadas (ver sección Resultados) que conforman el objeto central del presente trabajo, se puede observar una representación esquemática de cada una de las opciones generadas para las distintas variables y una imagen adaptada del banco de datos que ilustra dicha representación.

Cabe aclarar que los ejemplos utilizados en las Figuras 1 a 11 no tienen indicación de escala porque, además de que muchos de los originales no la tenían, se han tomado solamente con fines ilustrativos.
Estos ejemplos seleccionados, que constituyen solo una parte del total de las representaciones analizadas para la elaboración de la tipología, dan cuenta de toda la variabilidad observada. Fueron adaptados de los siguientes textos y piezas: Ambrosetti, 1899 (fig. 119, p. 135); Ambrosetti, 1906 (fig. 116, p. 109 y fig. 130, p. 118); Ambrosetti, 1907 (fig. 112, p. 243); Basile, 2005 (lám. 39, p. 130); Bedano, Juez y Roca, 1993 (fig. 19 - pieza 121, p. 62 y fig. 30 - pieza 63, p. 97); Bruch, 1911 (fig. 10, p. XV); De la Fuente, Nazar y Pelli, 2005 (p. 239); Falchi et al., 2011 (fig. 5, p. 45); Fernández Distel, 19831984 (fig. 4, p. 34); Fiadone, 2001 (p. 67, 108a, 108b, 175a y 175b); González, 1977 (fig. 219, p. 270); González, 1992 (pieza 223, lám. 24, pieza 352, lám. 41 y pieza 353, lám. 41); Goretti, 2006 (p. 201a, 201b y 230); Goretti, 2007 (p. 152); Lafone Quevedo, 1908 (fig. 48, p. 373); Schobinger y Gradin, 1985 (foto 98, p. 136); Sempé, 1998 (fig. 1 - pieza 11753 , p. 275 y fig. 3 - pieza 11498, p. 277); Sempé y Baldini, 2002 (fig. 1 pieza 12216, p. 251); Sempé y Baldini, 2004 (fig. 4 - pieza 11498, p. 283); Serrano, 1966 (fig. 46, p. 98); Piezas 261 y 586 (JUD 10817/00, Museo del Hombre, INAPL).

\section{Resultados}

Los resultados generados quedaron plasmados en 11 figuras. Para la representación completa se estableció si su vista era en planta o en planta / perfil. Para esta última opción, se consideraron casos en los que el cuerpo se presentaba en planta pero: a) la cabeza se ubicaba de perfil, con un solo ojo y boca o b) la cabeza se encontraba en planta con dos ojos y boca de perfil, ya sea cerrada o abierta (Figura 1). Asimismo, se tuvo en cuenta si el tipo de tratamiento de la figura era lineal, plano o si resultaba de la combinación de ambos (Figura 2).

Para la cabeza se estimó en primer término su contorno y forma. Dentro de los contornos curvos se registraron tres tipos de formas: a) circular (simple y con apéndices), b) semicircular y c) ovalada ( $\mathrm{Fi}$ gura 3a). Para los contornos rectos también se identificaron tres tipos de formas: a) triangular (simple -triángulo con base recta o triángulo invertidoy doble -triángulo con base doble o triángulos 


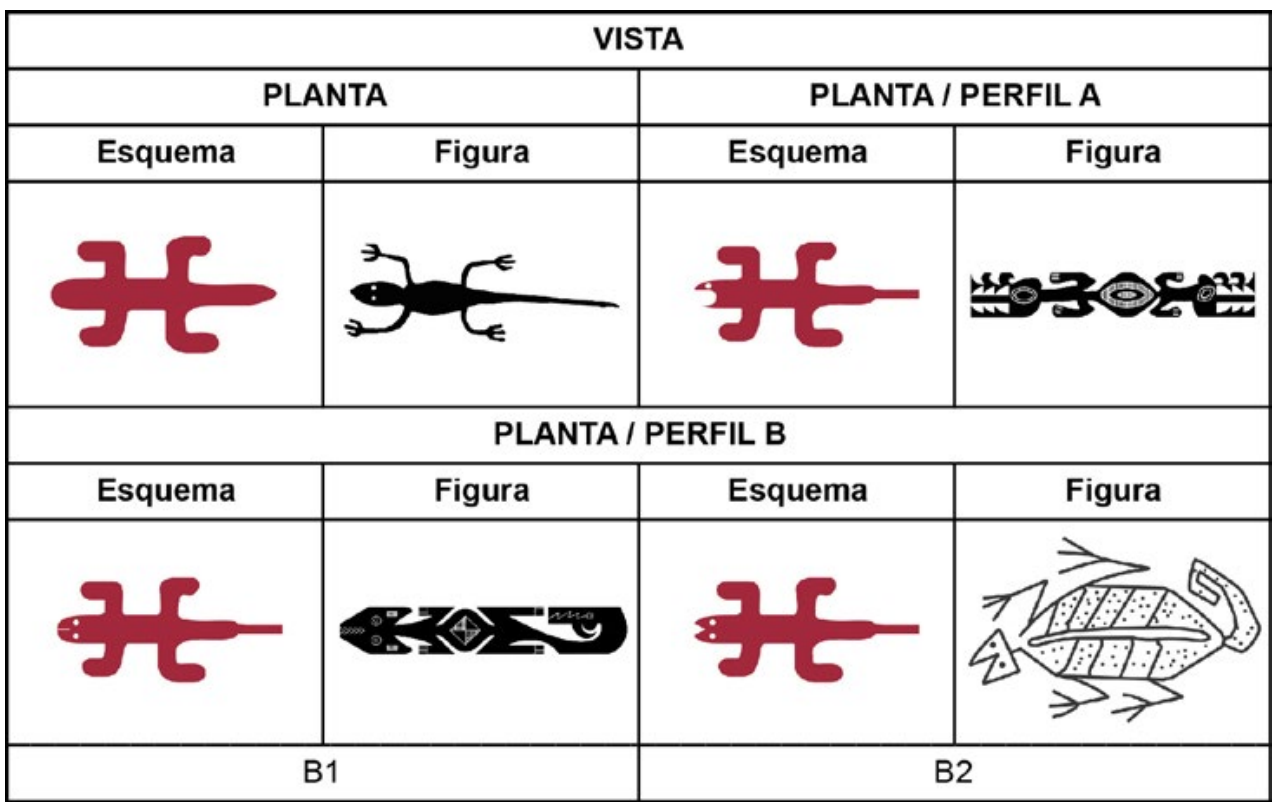

Figura 1. Opciones tipológicas para la vista.

\begin{tabular}{|c|c|}
\hline \multicolumn{2}{|c|}{ CABEZA, CUERPO, PATAS Y COLA - } \\
TIPO DE TRATAMIENTO \\
\hline LINEAL \\
\hline \multicolumn{2}{|c|}{ Figura } \\
\hline \multicolumn{2}{|c|}{ PLANO } \\
\hline Esquema
\end{tabular}

Figura 2. Opciones tipológicas para el tipo de tratamiento de la cabeza, el cuerpo, las patas y la cola. 
opuestos por la base-), b) rectangular y c) romboidal (simple y doble). Asimismo, se reconocieron ejemplos de contorno curvo / recto de forma irregular. Cuando la representación presentaba deterioro en el sector de la cabeza se la clasificó como no determinada, tanto para su contorno como para su forma (Figuras 3b y 3c). A su vez, se registró la presencia o ausencia de cinco atributos para la cabeza: ojos, boca, lengua, dientes y cuello, sin especificar su morfología (Figuras $4 \mathrm{a}$ y 4b).

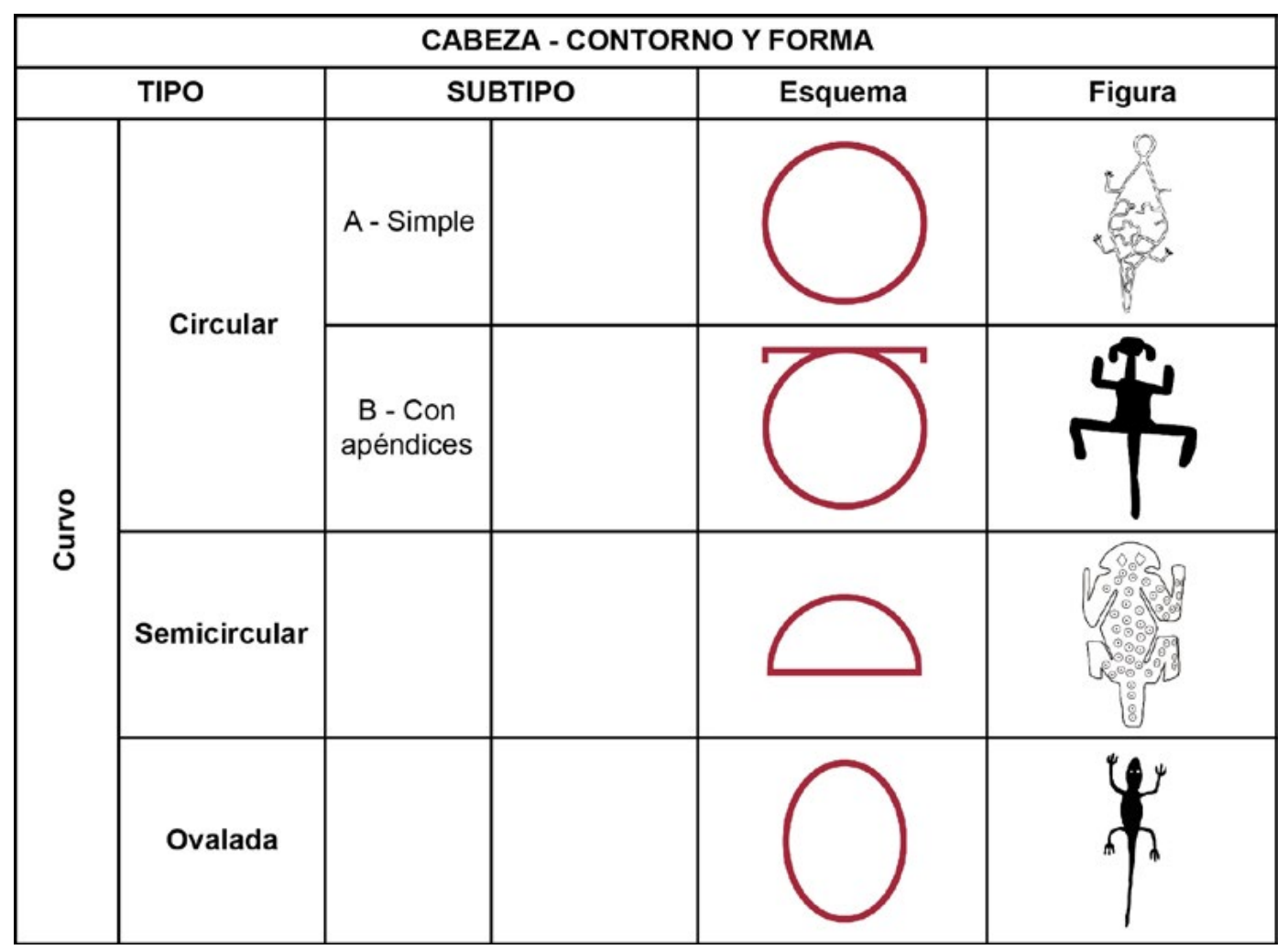

Figura 3a. Opciones tipológicas para el contorno y la forma de la cabeza. 


\begin{tabular}{|c|c|c|c|c|c|}
\hline \multicolumn{6}{|c|}{ CABEZA - CONTORNO Y FORMA } \\
\hline & TIPO & & 3TIPO & Esquema & Figura \\
\hline \multirow{4}{*}{$\begin{array}{l}\stackrel{9}{\mathrm{~d}} \\
\text { ¿ }\end{array}$} & \multirow{4}{*}{ Triangular } & \multirow{2}{*}{ A - Simple } & $\begin{array}{l}1 \text { - Triángulo } \\
\text { con base } \\
\text { recta }\end{array}$ & & $\frac{1}{7}$ \\
\hline & & & $\begin{array}{l}2 \text { - Triángulo } \\
\text { invertido }\end{array}$ & & \\
\hline & & \multirow{2}{*}{ B - Doble } & $\begin{array}{l}1 \text { - Triángulo } \\
\text { con base } \\
\text { doble }\end{array}$ & & \\
\hline & & & $\begin{array}{c}2 \text { - Triángulos } \\
\text { opuestos } \\
\text { por la base }\end{array}$ & & \\
\hline
\end{tabular}

Figura 3b. Opciones tipológicas para el contorno y la forma de la cabeza (continuación). 


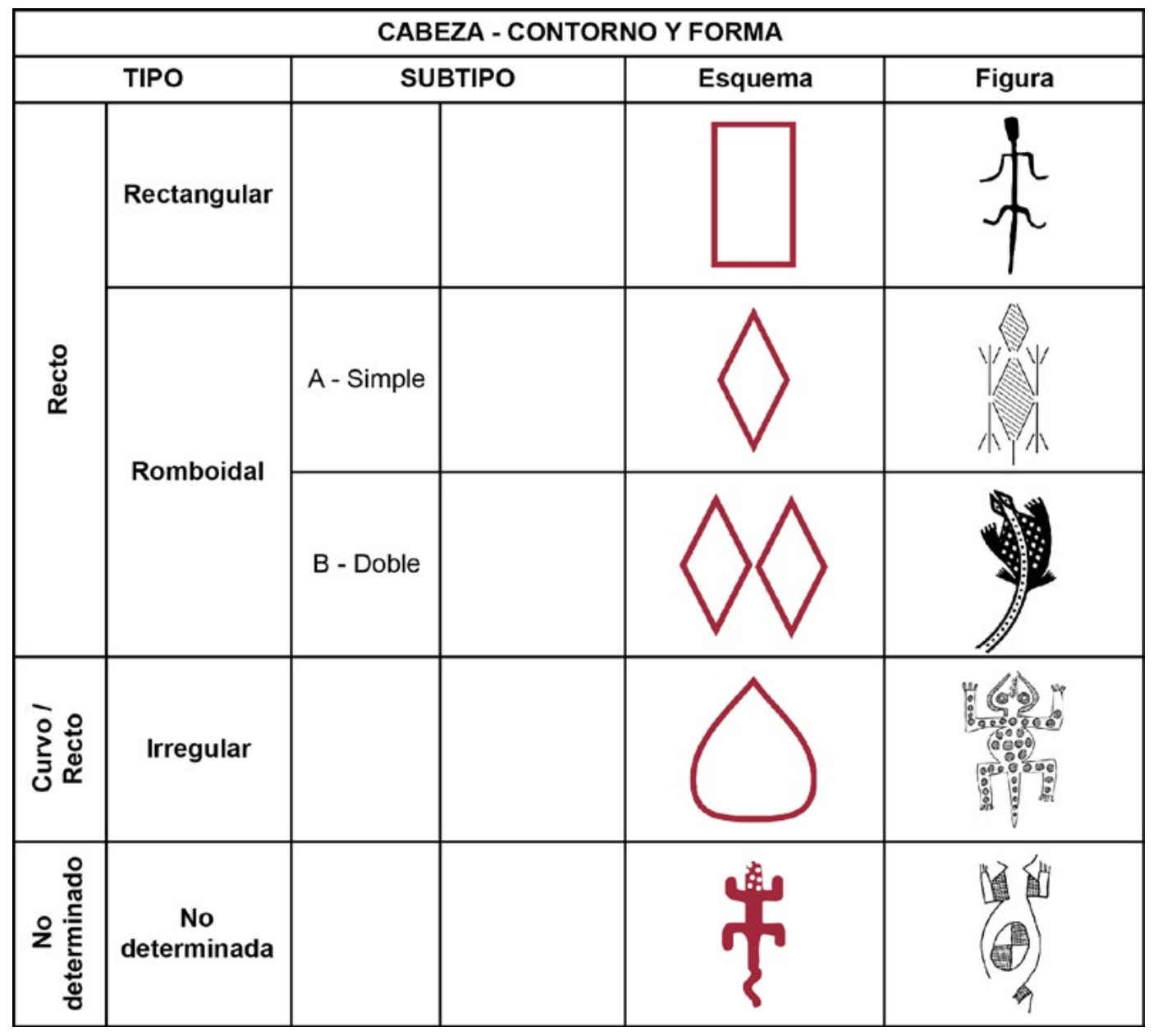

Figura 3c. Opciones tipológicas para el contorno y la forma de la cabeza (continuación). 


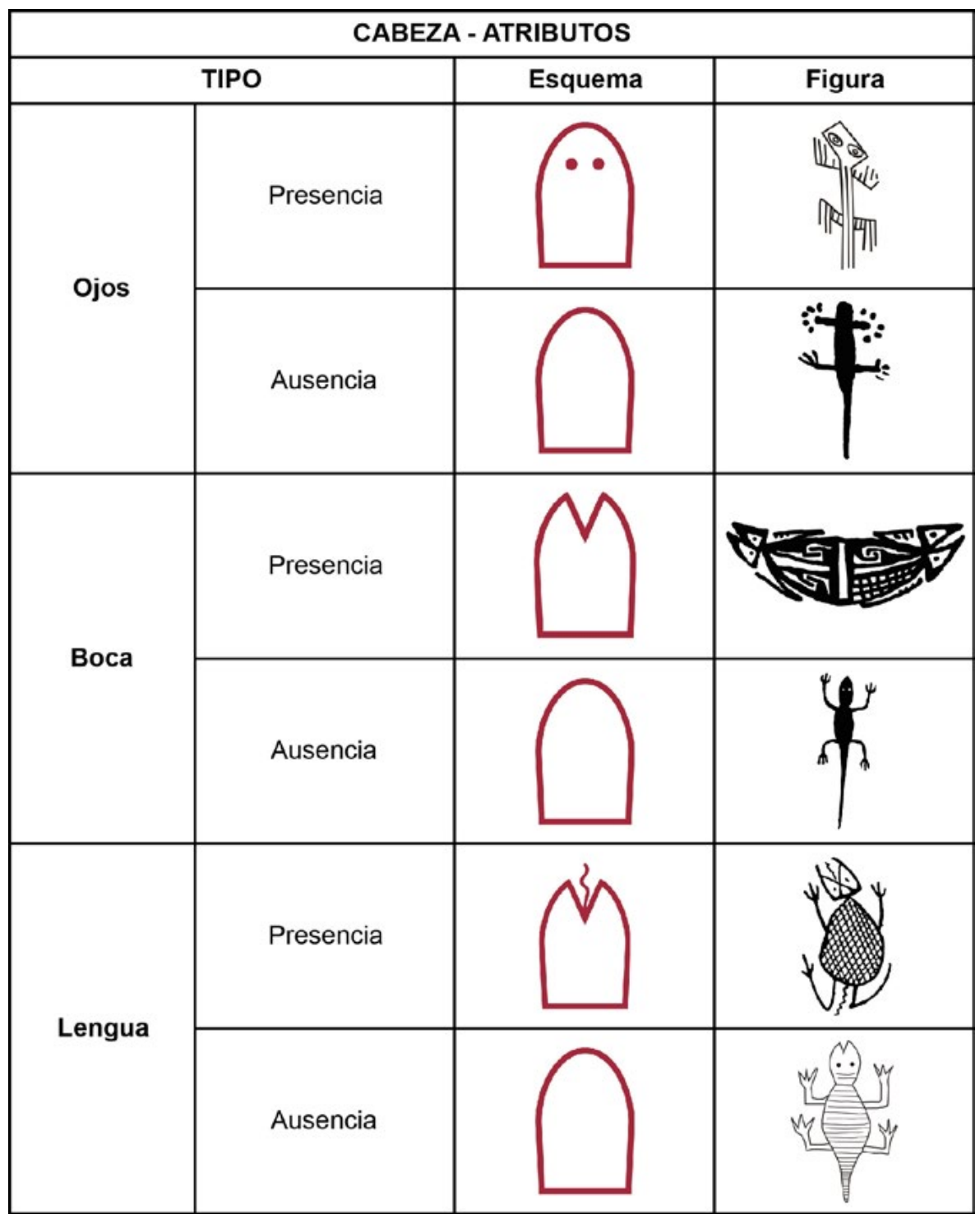

Figura 4a. Opciones tipológicas para los atributos de la cabeza. 




Figura 4b. Opciones tipológicas para los atributos de la cabeza (continuación). 
Para el cuerpo se consideró su contorno y forma. Dentro de los contornos curvos se incluyeron tres tipos de formas: circular, ovalada y almendrada ( $\mathrm{Fi}$ gura 5a). Para los contornos rectos se identificaron cuatro formas: lineal, rectangular, romboidal e irregular. En el caso de que el contorno se presentara curvo / recto se reconoció una sola forma: irregular (Figura 5b).

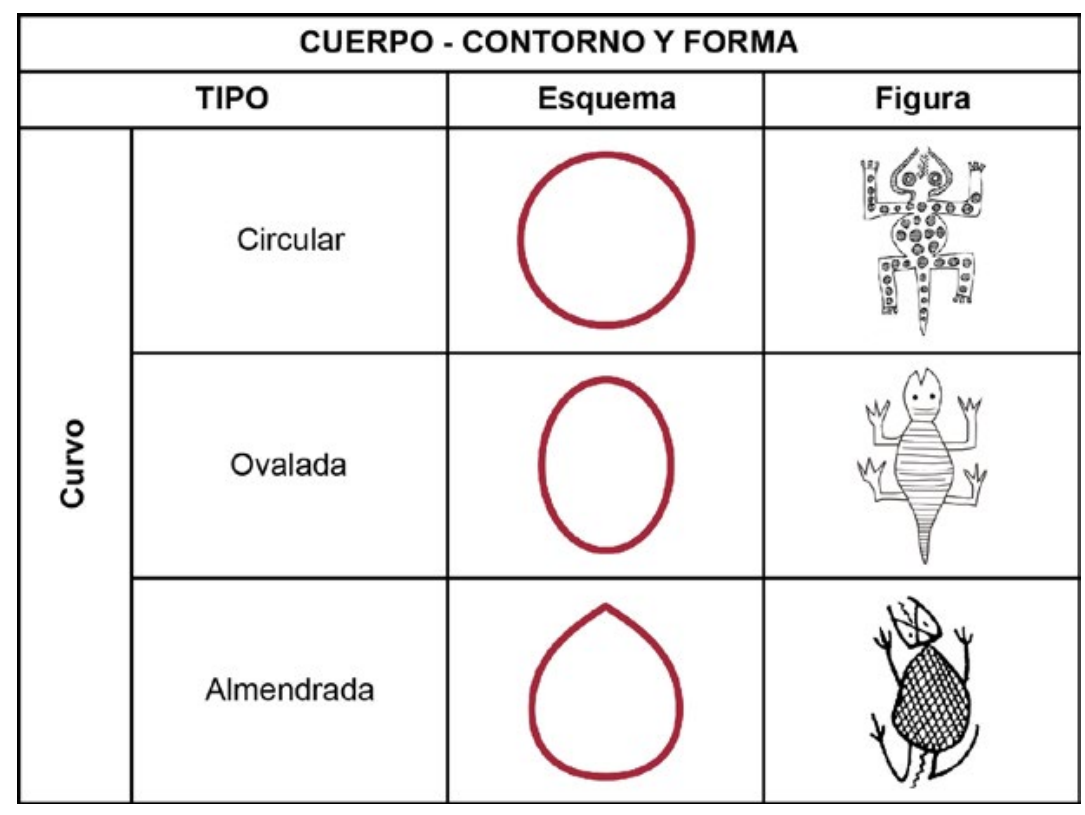

Figura 5a. Opciones tipológicas para el contorno y la forma del cuerpo. 


\begin{tabular}{|c|c|c|c|}
\hline \multicolumn{4}{|c|}{ CUERPO - CONTORNO Y FORMA } \\
\hline & TIPO & Esquema & Figura \\
\hline \multirow{4}{*}{ 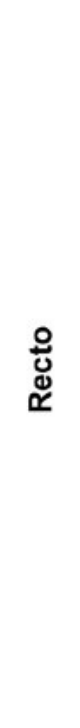 } & Lineal & & \\
\hline & Rectangular & & \\
\hline & Romboidal & & \\
\hline & Irregular & & \\
\hline ○ 엉 & Irregular & & \\
\hline
\end{tabular}

Figura 5b. Opciones tipológicas para el contorno y la forma del cuerpo (continuación). 
Para las patas se tuvo en cuenta su posición y orientación. Cuando las patas se presentaban flexionadas, se identificaron cuatro variantes: a) 4 patas flexionadas hacia arriba, b) 4 patas flexionadas hacia abajo, c) 2 patas flexionadas hacia arriba y 2 patas flexionadas hacia abajo y d) 2 patas flexionadas hacia arriba (Figura 6a). Cuando las patas se presentaban extendidas, se establecieron dos variantes: a) 2 patas extendidas hacia arriba y 2 patas extendidas hacia abajo, paralelas al cuerpo y b) 4 patas extendidas, perpendiculares al cuerpo. En los casos en los que en una misma figura se presentaban patas tanto extendidas como flexionadas, éstas se clasificaron como combinadas. Esta categoría agrupó tres posibilidades: a) 2 patas flexionadas hacia arriba / abajo y 2 patas extendidas, perpendiculares al cuerpo, b) 2 patas flexionadas hacia arriba y 2 patas extendidas hacia arriba, paralelas al cuerpo y c) 2 patas flexionadas hacia arriba y 2 patas indeterminadas por deterioro. Además se observó la posibilidad de que las patas se representaran adosadas al cuerpo. En este caso, todos los ejemplos presentaban las 4 patas de la misma manera (Figura 6b).

Para la terminación de las patas se consideró la forma de los dedos, determinándose siete tipos: bifurcados, peiniformes (sin base y con base), con segmentos horizontales, con cabezas de felino, con cabezas de camélido, combinados y no corresponde (Figuras $7 \mathrm{a}$ y $7 \mathrm{~b}$ ).

\begin{tabular}{|c|c|c|c|}
\hline \multicolumn{4}{|c|}{ PATAS - POSICIÓN Y ORIENTACIÓN } \\
\hline & TIPO & Esquema & Figura \\
\hline \multirow{4}{*}{$\begin{array}{l}\stackrel{0}{0} \\
\frac{\pi}{0} \\
\mathbb{\pi} \\
\frac{0}{x} \\
\frac{0}{4}\end{array}$} & $\begin{array}{c}\text { A - } 4 \text { patas flexionadas } \\
\text { hacia arriba }\end{array}$ & & \\
\hline & $\begin{array}{c}\text { B - } 4 \text { patas flexionadas } \\
\text { hacia abajo }\end{array}$ & & \\
\hline & $\begin{array}{c}\text { C - } 2 \text { patas flexionadas } \\
\text { hacia arriba y } \\
2 \text { patas flexionadas } \\
\text { hacia abajo }\end{array}$ & & \\
\hline & $\begin{array}{c}\text { D - } 2 \text { patas flexionadas } \\
\text { hacia arriba }\end{array}$ & & \\
\hline
\end{tabular}

Figura 6a. Opciones tipológicas para la posición y la orientación de las patas. 


\begin{tabular}{|c|c|c|c|}
\hline \multicolumn{4}{|c|}{ PATAS - POSICIÓN Y ORIENTACIÓN } \\
\hline & TIPO & Esquema & Figura \\
\hline \multirow{2}{*}{ 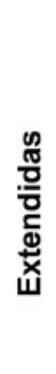 } & $\begin{array}{c}\text { A - } 2 \text { patas extendidas } \\
\text { hacia arriba y } \\
2 \text { patas extendidas } \\
\text { hacia abajo, } \\
\text { paralelas al cuerpo }\end{array}$ & & \\
\hline & $\begin{array}{l}\text { B - } 4 \text { patas extendidas, } \\
\text { perpendiculares al cuerpo }\end{array}$ & & \\
\hline \multirow{3}{*}{  } & $\begin{array}{l}\text { A - } 2 \text { patas flexionadas } \\
\text { hacia arriba / abajo y } \\
2 \text { patas extendidas, } \\
\text { perpendiculares al cuerpo }\end{array}$ & & \\
\hline & $\begin{array}{c}\text { B - } 2 \text { patas flexionadas } \\
\text { hacia arriba y } \\
2 \text { patas extendidas } \\
\text { hacia arriba, } \\
\text { paralelas al cuerpo }\end{array}$ & & \\
\hline & $\begin{array}{c}\text { C - } 2 \text { patas flexionadas } \\
\text { hacia arriba y } \\
2 \text { patas indeterminadas }\end{array}$ & & \\
\hline $\begin{array}{l}\frac{9}{\pi} \\
\frac{\pi}{\pi} \\
\frac{\pi}{0} \\
\frac{0}{0} \\
\frac{0}{\alpha}\end{array}$ & $\begin{array}{c}\text { A - } 4 \text { patas adosadas } \\
\text { al cuerpo }\end{array}$ & & \\
\hline
\end{tabular}

Figura 6b. Opciones tipológicas para la posición y la orientación de las patas (continuación). 


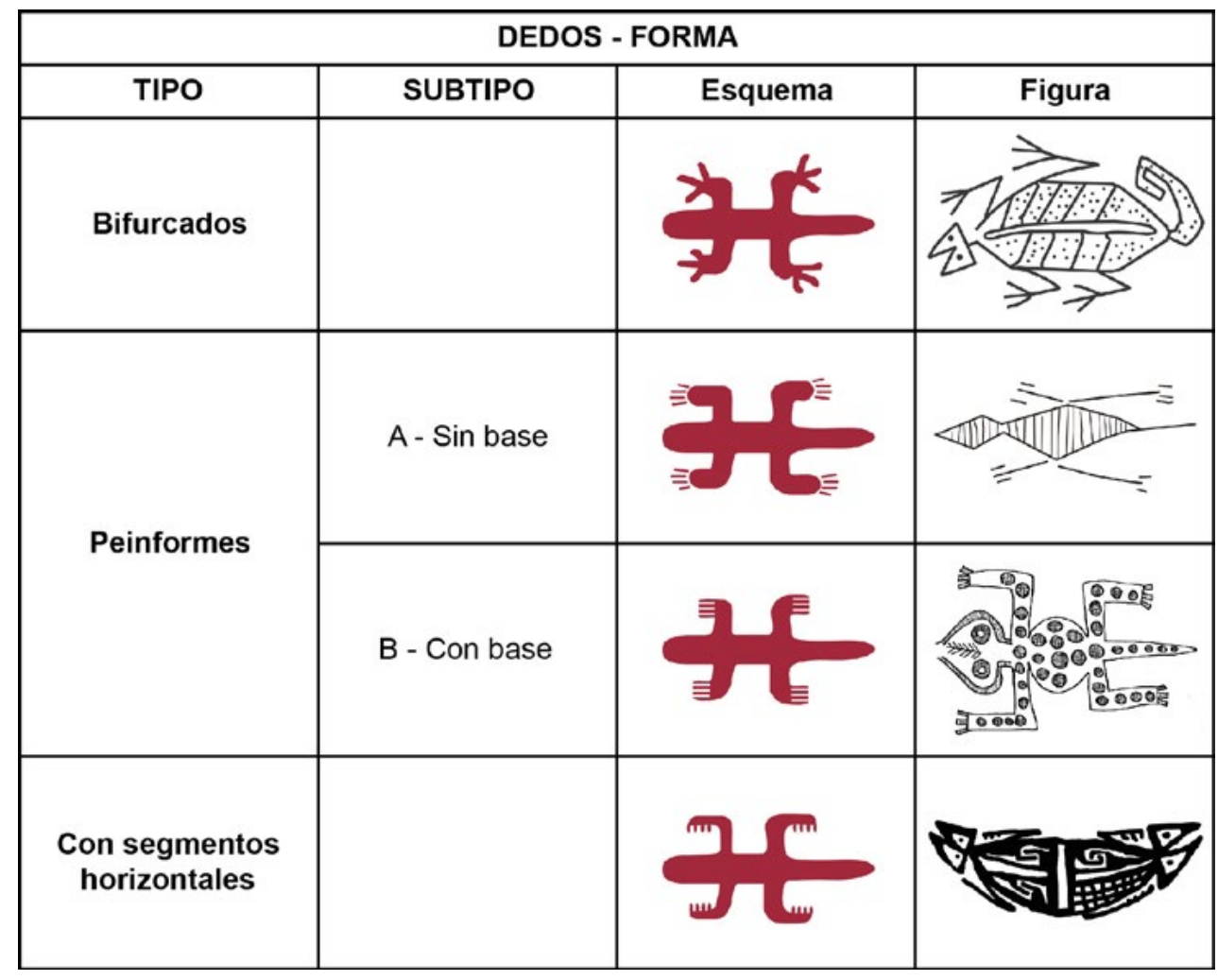

Figura 7a. Opciones tipológicas para la forma de los dedos. 


\begin{tabular}{|c|c|c|c|}
\hline \multicolumn{2}{|c|}{ DEDOS - FORMA } \\
\hline $\begin{array}{c}\text { Con cabezas } \\
\text { de felino }\end{array}$ & SUBTIPO & Esquema & \\
\hline $\begin{array}{c}\text { Con cabezas } \\
\text { de camelido }\end{array}$ & & & \\
\hline & & & \\
\hline Combinados & & & \\
\hline No corresponde & & & \\
\hline
\end{tabular}

Figura $7 \mathbf{b}$. Opciones tipológicas para la forma de los dedos (continuación). 
Con respecto a la cola, en primer término se calificó su forma. Se establecieron seis tipos: recta, curva, sinuosa, doble en zigzag, no corresponde y no determinada (Figura 8). En segundo lugar se analizó su terminación. Para esta variable se identificaron ocho tipos: recta, curva, en punta, abierta, tumiforme, con cabeza de felino, no corresponde y no determinada (Figuras 9a y 9b).

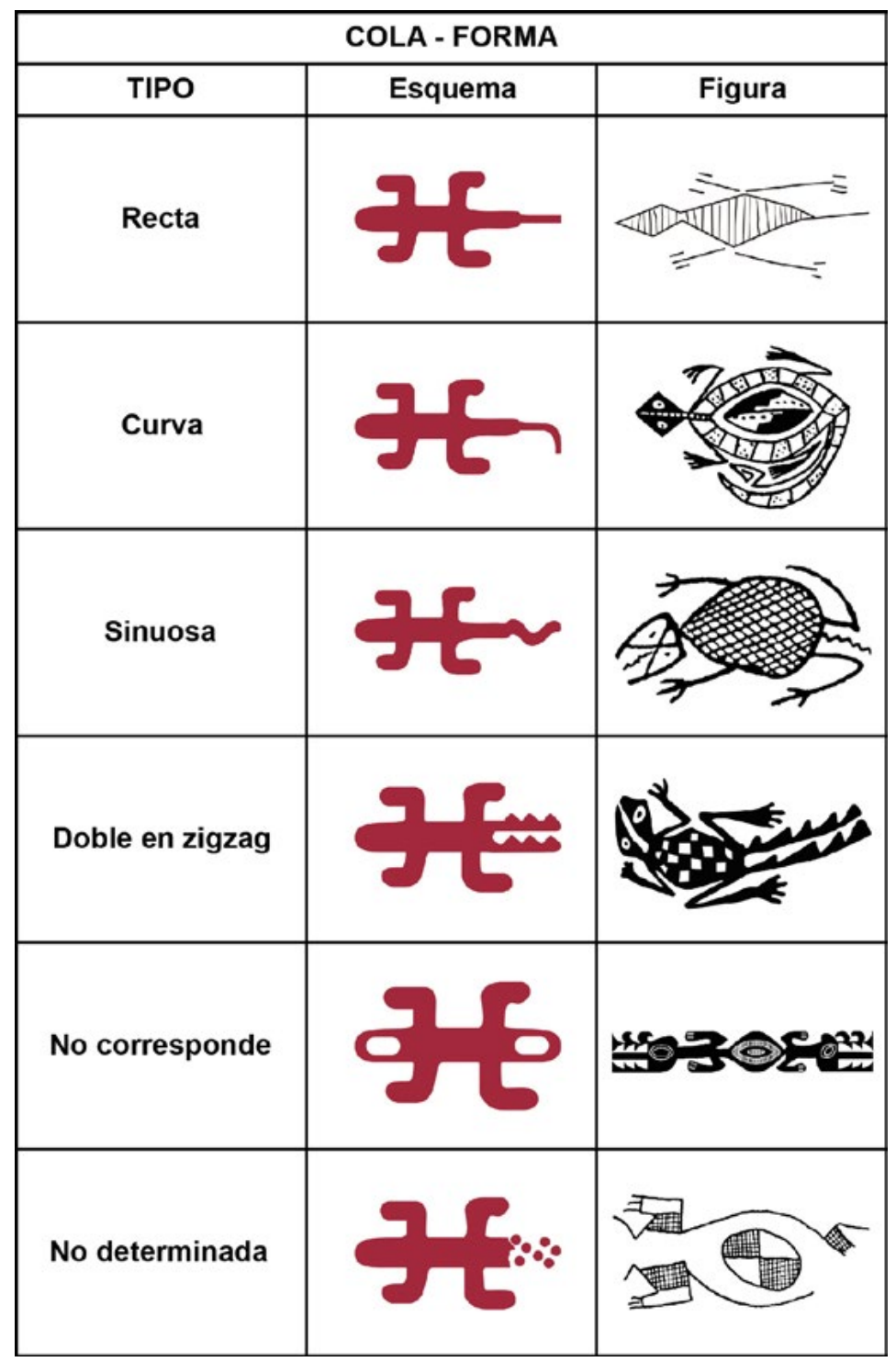

Figura 8. Opciones tipológicas para la forma de la cola. 


\begin{tabular}{|c|c|c|}
\hline \multicolumn{3}{|c|}{ COLA - TERMINACIÓN } \\
\hline TIPO & Esquema & Figura \\
\hline \multicolumn{3}{|l|}{ Recta } \\
\hline \multicolumn{3}{|l|}{ Curva } \\
\hline \multicolumn{3}{|c|}{ En punta } \\
\hline \multicolumn{3}{|l|}{ Abierta } \\
\hline & & \\
\hline
\end{tabular}

Figura 9a. Opciones tipológicas para la terminación de la cola. 


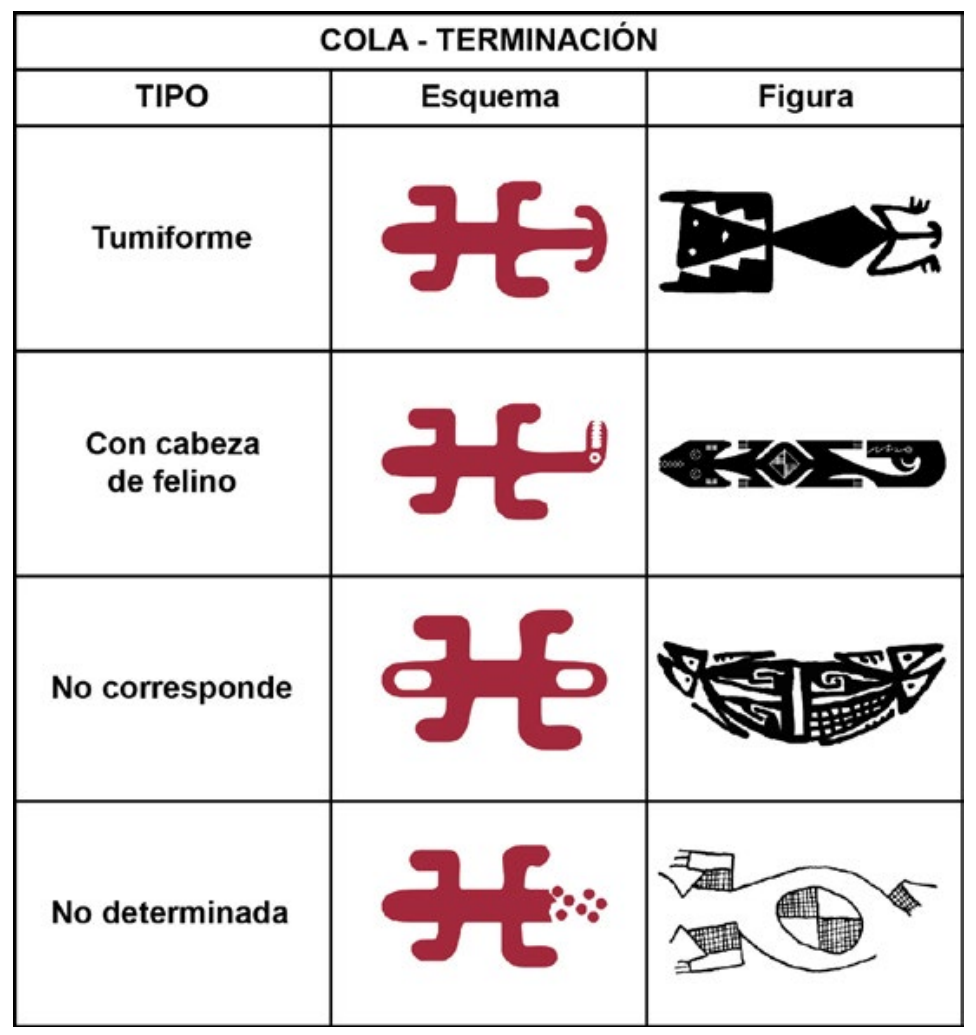

Figura 9b. Opciones tipológicas para la terminación de la cola (continuación).

Se registraron diseños internos en las diferentes partes del cuerpo: cabeza, cuerpo, patas y cola. Se reunieron todas las variantes observadas en una sola figura: puntos / trazos, círculos, círculos con punto, líneas horizontales paralelas, líneas verticales paralelas, líneas diagonales paralelas, líneas sinuosas, rombo(s), reticulado, damero, triángulos espiralados con o sin apéndice, combinado, no corresponde y no determinado (Figuras 10a y 10b). 


\begin{tabular}{|c|c|c|c|}
\hline \multicolumn{4}{|c|}{ CABEZA, CUERPO, PATAS Y COLA - DISEÑOS INTERNOS } \\
\hline \multicolumn{2}{|c|}{ TIPO } & Esquema & Figura \\
\hline Puntos & Puntos / Trazos & & \\
\hline \multirow{2}{*}{ Círculos } & Circulos & $\begin{array}{lll}0 & 0 & 0 \\
0 & 0 & 0 \\
0 & 0 & 0 \\
0 & 0 & 0 \\
\end{array}$ & 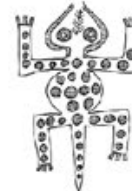 \\
\hline & $\begin{array}{l}\text { Círculos } \\
\text { con punto }\end{array}$ & & \\
\hline \multirow{4}{*}{ Líneas } & $\begin{array}{c}\text { Líneas } \\
\text { horizontales } \\
\text { paralelas }\end{array}$ & & \\
\hline & $\begin{array}{c}\text { Líneas } \\
\text { verticales } \\
\text { paralelas }\end{array}$ & & \\
\hline & $\begin{array}{c}\text { Líneas } \\
\text { diagonales } \\
\text { paralelas }\end{array}$ & & \\
\hline & $\begin{array}{l}\text { Líneas } \\
\text { sinuosas }\end{array}$ & & \\
\hline
\end{tabular}

Figura 10a. Opciones tipológicas para los diseños internos de la cabeza, el cuerpo, las patas y la cola. 


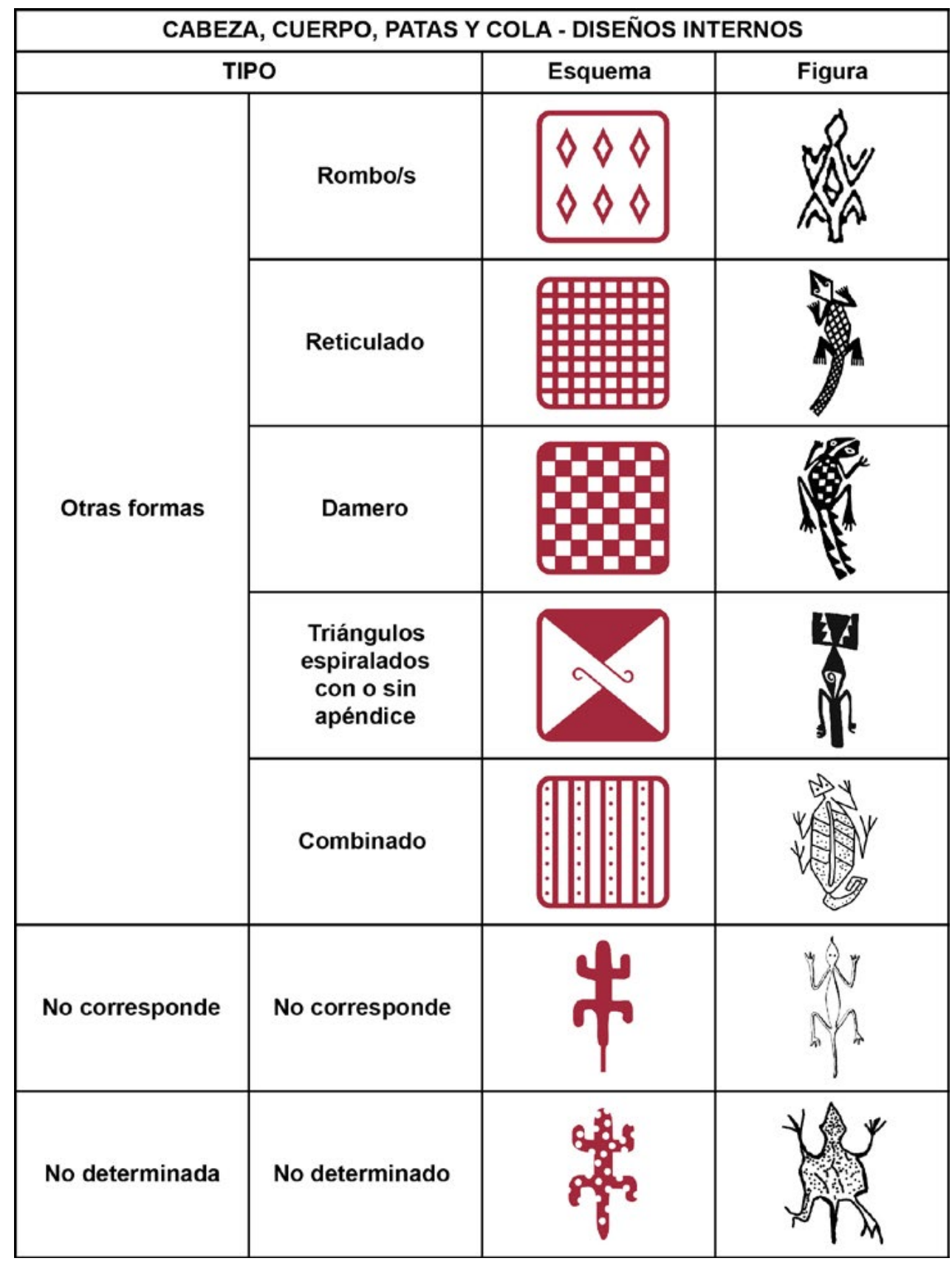

Figura 10b. Opciones tipológicas para los diseños internos de la cabeza, el cuerpo, las patas y la cola (continuación). 
Por último, se consideró cómo se articulaban las partes del cuerpo, es decir, el tipo de unión entre: a) cabeza y cuerpo, b) cuerpo y patas y c) cuerpo y cola. En los casos en los que el trazo no presentara interrupciones entre las partes, se lo juzgó como continuo; y en los ejemplos en que se observara un cambio abrupto en el trazo, se lo calificó como discontinuo. Para el tipo de unión entre cuerpo y cola, de la misma manera que en las figuras anteriores, se consideraron las opciones de no corresponde y no determinado (Figura 11).

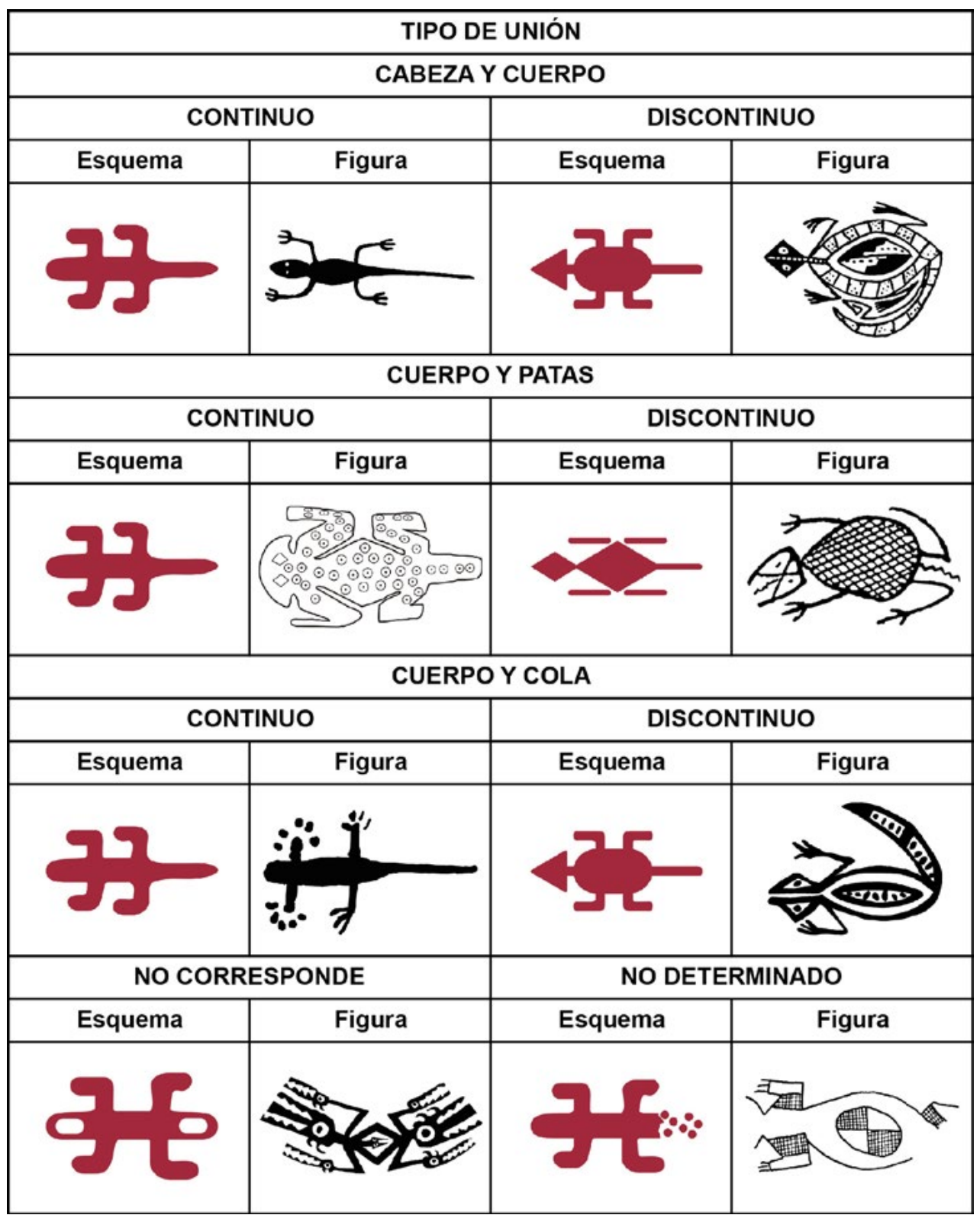

Figura 11. Opciones tipológicas para el tipo de unión entre la cabeza y el cuerpo, el cuerpo y las patas y el cuerpo y la cola. 


\section{Discusión y consideraciones finales}

\section{Acerca de la tipología elaborada y del modo de representación de las lagartijas en la iconografía prehispánica del NOA}

Como el término 'lagartija' alude a un grupo de saurios distintos, la gran variabilidad en las maneras de representarlos probablemente responda a la diversidad de familias, géneros y especies existentes que, a partir de la ambigüedad de las figuras, resultan imposibles de identificar. A modo de ejemplo, en un trabajo herpetológico publicado en el año 2013 se menciona un mínimo de 261 especies de lagartijas descriptas para la República Argentina (Ávila, Martínez y Morando, 2013).

Mientras que algunos patrones son muy abundantes y ubicuos, otros solo están presentes en unos pocos casos. Otras características son típicas de algunos períodos (p.e., Desarrollos Regionales) o de algunos soportes (p.e., metalurgia).

La Vista (ver Figura 1) surge de la combinación de la manera de representar cabezas y cuerpos. Resulta llamativo que no haya lagartijas solo de perfil, al igual que ocurre en la mayoría de los casos de ofidios del período de Integración Regional (Kligmann y Díaz País, 2007). Por lo tanto, hay dos maneras posibles de representar la vista: planta y planta / perfil. Dentro de esta última se consideraron dos alternativas que combinan elementos de la realidad, pero de manera tal que no existen en la naturaleza: a) cuerpo en vista dorsal y cabeza en vista lateral, con un solo ojo y una boca, y b) cuerpo y cabeza en vista dorsal, con dos ojos y boca (ya sea abierta o cerrada) que simula estar de perfil. De cualquier manera, las bocas no tienen labios y casi no se notan cuando están cerradas. Por lo tanto, el animal es real, pero la forma de representarlo no necesariamente lo es.

En el Tipo de tratamiento (ver Figura 2) se registró que las figuras de tratamiento plano son las que presentan menor cantidad de detalles decorativos, las de tratamiento lineal pueden combinar diferentes formas geométricas, mientras que las de tratamiento lineal / plano son las más elaboradas por el grado de complejidad de los diseños que involucran. Estas últimas se registran en general en pintura sobre cerámica, mientras que las de tratamiento tanto lineal como plano no parecerían depender del soporte.

La Cabeza (ver Figuras 2, 3a, 3b, 3c, 4a, 4b, 10a y $10 \mathrm{~b})$ presenta múltiples combinaciones en cuanto a su tratamiento, contorno, forma, atributos y diseños internos. La complejidad de las formas de las cabezas nos llevó a crear varios subtipos para cada uno de los tipos descriptos dada la gran variabilidad observada al interior de algunas de las categorías.

No se observó una correlación entre la forma de la cabeza y la del cuerpo: por ejemplo, las cabezas triangulares pueden estar combinadas con cuerpos ovalados, almendrados o romboidales.

En cuanto a los atributos de la cabeza, también se aprecia una gran variabilidad en sus combinaciones. Cabe aclarar que no se ha tenido en cuenta el atributo 'nariz' que en la naturaleza se presenta como dos pequeńos orificios poco perceptibles en el extremo del hocico, ya que no fue registrada en ninguna de las figuras de la base de datos.

El hecho de que la mayoría de las lagartijas esté representada en planta e incluya ojos indica una perspectiva forzada de la realidad, ya que cuando los animales están en planta no se les ven los ojos. La misma situación sucede con las bocas, ya que cuando las lagartijas están representadas en planta, éstas no deberían verse, como sí sucede cuando se las observa de perfil.

La lengua, más asociada a las víboras venenosas, no tendría la misma connotación en las representaciones de las lagartijas ya que no se trata de animales venenosos, aunque el folklore les atribuye esta característica a algunas especies en particular (Palermo, 1984a; Adriana Albino, com. pers.). En el caso de la presencia de dientes, se podría estar representando más un lagarto que una lagartija y siempre se observan cuando la boca está abierta. Algunos de los ejemplos aquí considerados como lagartijas, correspondientes al período de Integración Regional, fueron descriptos como felinos por otros autores, como por ejemplo González (1977). La presencia / ausencia 
de estos dos atributos (lengua y dientes) resulta en casos de adscripción animal ambigua.

Si bien en la naturaleza las lagartijas no presentan un cuello estilizado, en algunos de los ejemplos relevados este atributo es muy notorio, mientras que en otros casos pasa casi inadvertido o es inexistente.

Casi todas las variantes de forma observadas para los Cuerpos (ver Figuras 5a y 5b) tienen en común ser más largas que anchas, una de las características básicas para que una figura sea considerada lagartija. Estas formas remiten a diversas figuras geométricas: circular, ovalada, almendrada, lineal, rectangular, romboidal e irregular, no habiendo encontrado ningún ejemplo que se apartara de estas tendencias. En resumen, a diferencia de las formas de las cabezas, los tipos descriptos para el cuerpo no se dividen en subtipos.

A priori no se consideró que las Patas (ver Figuras 6a y 6b) presentaran tanta variabilidad en su modo de representación. Por el contrario, se esperaba que la mayoría fuera del tipo "2 patas flexionadas hacia arriba y 2 patas flexionadas hacia abajo", pero el análisis detallado reveló 10 opciones, transformándola en una variable muy rica. De la misma manera que con otras partes del cuerpo, la representación de las patas no responde a la biología ya que, por ejemplo, no existen especies que tengan sus cuatro patas extendidas y perpendiculares al cuerpo. Además, algunas de las opciones de representación de las patas remiten a otros animales como anfibios y roedores. No se observó una correlación entre la forma del cuerpo y la de las patas (por ejemplo, los cuerpos ovalados pueden tener patas flexionadas, extendidas o combinadas).

Respecto de los Dedos (ver Figuras 7a y 7b), sorprendió la gran variedad de tipos registrados. Aquí también se observó que algunas de las formas de los dedos son características de otros animales como felinos y camélidos.

Una vez establecido que se consideraba la representación de la Cola cuando fuese más larga que las patas, su forma no presentó mayor variabilidad (solo cuatro opciones sin tener en cuenta los tipos no co- rresponde y no determinado) (ver Figura 8). En lo que respecta a su terminación, se trata en general de formas simples, salvo un caso que fue más allá de lo esperado y que fue clasificado como tumiforme (ver Figuras 9a y 9b). Nuevamente en este caso, al igual que en la forma de representación de las patas y la forma de los dedos, se presenta la combinación de distintos animales en una misma figura. Por ejemplo, en el conjunto analizado se puede apreciar una lagartija cuya cola termina en la cabeza de un felino. Esto remite a criaturas imaginarias, ficticias, mitológicas o fantásticas como el centauro, que combina en un mismo individuo la cabeza, los brazos y el torso de un humano con el cuerpo y las patas de un caballo.

A partir de la tipología se puede observar que la variable que presenta más opciones (12 tipos) es la de Diseńos internos (ver Figuras 10a y 10b). Cabe aclarar que se incluyeron opciones tanto de cabezas, cuerpos, patas y colas, mientras que en otras figuras estas cuatro partes del cuerpo se presentaban por separado. Los tipos identificados no se apartan de aquellos observados en la iconografía prehispánica en general, pudiendo ser registrados en diversos materiales, ya sea de manera individual o combinados.

Respecto del Tipo de unión (ver Figura 11), no siempre se observan las mismas modalidades en las diferentes partes del cuerpo. Por ejemplo, cuando la unión entre cabeza y cuerpo es continua, la unión entre cuerpo y patas y entre cuerpo y cola puede ser tanto continua como discontinua. Es decir, que en un mismo motivo se combinan distintos tipos de uniones.

\section{Acerca de autores, observadores, lagartijas y clasificaciones}

Aun reconociendo las diferentes habilidades y experiencia de los autores, se considera que existen patrones culturales que trascienden lo individual. A su vez, cada materia prima impone límites técnicos que influyen en la representación final. A todos estos factores de interpretación de las representaciones se les suma la ambigüedad resultante de la combinación de atributos de diferentes especies en una misma figura. La ambigüedad no es inocente 
sino que es intencional, con el fin de transmitir un determinado mensaje.

Asimismo, en este análisis se reconoce la subjetividad del observador. Independientemente de las habilidades del autor (no es posible acceder a su pensamiento). También hay que tener en cuenta los conocimientos de las personas que miran las imágenes y su experiencia. Una misma figura puede dar lugar a interpretaciones varias. Un ejemplo de esto lo constituye el test de Rorschach en el cual, frente a figuras ambiguas y con falta de estructuración, cada individuo las interpreta dentro de sus propias limitaciones. En relación a este test, entre los factores que afectan la imagen final percibida se pueden mencionar la inversión de figuras y fondo, la relación entre formas y colores, la posición y la sensación de movimiento (Arnheim, 1985).

Finalmente, existe una tercera opción que sería la del observador-investigador. Sus apreciaciones van más allá de una simple mirada y tampoco son inocentes, ya que involucran un análisis pormenorizado pero a una escala amplia a nivel espacial y temporal, tratando de responder determinados interrogantes.

Con respecto a las apreciaciones del observadorinvestigador, cabe mencionar que la distribución actual de las lagartijas y otros saurios no necesariamente coincide con la del pasado. Por lo tanto, no es posible guiarse solamente por las especies que hoy en día viven en el NOA para interpretar las representaciones. Como se ha comprobado a lo largo de este trabajo, éstas no necesariamente responden a animales que existan de esa manera en la realidad. Uno no ve lo que no sabe que existe, por lo que tal vez algunas de estas 'lagartijas' sean en realidad yacarés, pero como no viven en esta región actualmente ni siquiera se considera esta posibilidad. El hecho de tratar de diferenciar entre animales varios dentro de los saurios puede abrir las puertas a encontrar información que no se está buscando. Así, la presencia de motivos de animales de otros ambientes en la zona de estudio puede remitir a relaciones de intercambio (los animales viajan o las representaciones de dichos animales viajan) (Núnez y Castro, 2011; Troncoso y Jackson, 2010) o incluso a cambios climáticos (Muzzolini, 1995).

\section{Algunas tendencias observadas}

A pesar de que la tipología aquí presentada constituye el primer paso de un trabajo de mayor alcance, en este acápite adelantamos algunas tendencias generales observadas por período que surgieron durante la elaboración de la tipología, las cuales son desarrolladas en detalle en otro artículo (Kligmann y Falchi, 2017).

Se ha observado que las lagartijas del período Formativo solo se representan en 'Planta', dominando el tratamiento 'Lineal' en todas las partes del cuerpo. Se destacan las formas 'Romboidales' tanto para las cabezas como para los cuerpos. Siempre presentan " 2 patas hacia arriba y 2 hacia abajo", en sus variantes extendidas o flexionadas. En las colas sobresalen las formas 'Rectas'. Cabe destacar que en el conjunto analizado domina la falta de decoración.

En el período de Integración Regional domina ampliamente la opción en 'Planta' así como el tratamiento 'Lineal' en todas las partes del cuerpo. Las lagartijas de este período son las que combinan más elementos o atributos de diferentes grupos animales en una misma figura. En las cabezas se observa un predominio de formas 'Romboidales', siendo éste el único período en el cual se registran todos los atributos de las cabezas. Abundan las patas flexionadas, en su combinación "2 hacia arriba y 2 hacia abajo". La mayoría de las figuras no presenta dedos ni decoración interna.

Las representaciones asignadas al período de Desarrollos Regionales no presentan un tipo predominante ni para la vista ni para el tratamiento de las figuras. Entre las formas de las cabezas son mayoría las 'Ovaladas' y se observan casi todos los atributos, excepto los dientes. La forma de las patas dominante es la de "2 flexionadas hacia arriba y 2 flexionadas hacia abajo". Entre los dedos predominan los 'Bifurcados'. En lo que respecta a las colas, abundan aquellas 'Rectas', siendo mayoría las figuras sin diseños internos. 


\section{Consideraciones finales}

La elaboración de la tipología fue un proceso dinámico entre las figuras y la base de datos, de revisión de las variables elegidas y de las opciones para cada una de las variables. No es lo mismo crear una tipología con figuras completas que descomponer esas figuras en sus partes anatómicas constitutivas (cabezas, cuerpos, etc.). Como resultado, se multiplicó la cantidad de opciones y de combinaciones posibles.

Lo difícil no fue clasificar sino elegir las variables. Con la tipología ya elaborada y la clasificación de las figuras realizada, encontrar patrones en el modo de representación de las lagartijas del NOA será un proceso más sencillo y sistemático. La combinación de la base de datos con la tipología elaborada nos permitirá buscar tendencias en el modo de representación de las lagartijas en diferentes períodos y soportes, identificando atributos utilizados con exclusividad para estos zoomorfos así como atributos compartidos con otros animales (humanos, batracios y reptiles -serpientes y tortugas-). A lo largo del análisis realizado se registraron casos de la asociación o combinación de elementos de diferentes grupos animales en una misma figura (p.e., camélidos, felinos y draconiformes) (Kligmann y Falchi, 2017).

Si una tipología se crea a partir de los restos materiales de una región y no de una colección individual, ésta será de utilidad para agrupar materiales que van más allá de un sitio en particular. Es decir, que cuanto mayor y más diversa sea la muestra a partir de la cual se elabora una tipología, mayor será su aplicabilidad para otros casos (Rice, 1997).

La tipología aquí desarrollada tomó en cuenta representaciones del NOA. Para esculturas o representaciones de otras regiones no necesariamente serviría y habría que adaptarla, ya que la variabilidad encontrada en las imágenes recopiladas no agota todas las opciones. Se cuenta con ejemplos de otras regiones de Argentina y de Chile, Bolivia y Perú donde estos animales están representados de manera diferente (Kligmann, 2009; Kligmann y Falchi, 2016).

El presente trabajo se propuso discutir conceptos relacionados con los alcances y limitaciones de las tipologías para interpretar representaciones, reflexionando acerca de las herramientas analíticas y los presupuestos teóricos incorporados a la práctica profesional. En este caso se eligió definir y discutir la unidad de análisis -la lagartija- para luego descomponer las figuras que calificaban en ese universo establecido en unidades menores (p.e., las partes del cuerpo), lo que permitió aproximarse al modo de representación desde una óptica diferente.

Asimismo, se tomó en cuenta un animal poco representado y, por lo tanto, escasamente estudiado en la arqueología prehispánica, a diferencia de otros como las serpientes y los camélidos, que son ubicuos en distintos períodos y/o regiones. Se consideró relevante dar cuenta de todos los animales representados independientemente de su abundancia o escasez, dado que su mayor o menor presencia también es informativa. Toda representación implica una elección ya que, como es sabido, no se representa todo lo que existe en el entorno, así como también pueden representarse elementos exóticos o imaginarios.

Si bien la tipología morfológica presentada es preliminar y exploratoria, por lo que deberá ponerse a prueba en futuras investigaciones, tiene la ventaja de plantear múltiples y variadas inquietudes así como de abrir vías para explorar.

\section{Agradecimientos}

A todos aquellos colegas que nos facilitaron bibliografía e imágenes. A Adriana Albino, porque su asesoramiento en cuestiones herpetológicas resultó fundamental para discutir algunas de las cuestiones planteadas en este trabajo. Por su excelente predisposición para responder todas y cada una de nuestras inquietudes. A Kevin Lane por revisar el abstract del trabajo. A Gisela Spengler por su invalorable colaboración para la edición final de las figuras. A los evaluadores cuyos comentarios contribuyeron a enriquecer el manuscrito original. 


\section{Referencias citadas}

Albino, A. M. y Kligmann, D. M. (2007). An accumulation of bone remains of two Liolaemus species (Iguanidae) in an Holocene archaeological site of the Argentine Puna. Amphibia-Reptilia, 28(1), 154-158.

Albino, A. M. y Kligmann, D. M. (2009). Inusual hallazgo de anfisbénidos (Squamata, Amphisbaenidae) en un yacimiento arqueológico de Argentina. Revista Española de Herpetología, 23, 99-106.

Ambrosetti, J. B. (1899). Notas de Arqueología Calchaqui (Primera Serie). Buenos Aires: "La Buenos Aires".

Ambrosetti, J. B. (1906). Exploraciones arqueológicas en la Pampa Grande (provincia de Salta). Revista de la Universidad de Buenos Aires V (Publicaciones de la Sección Antropológica $N^{\circ}$ 1, Facultad de Filosofía y Letras).

Ambrosetti, J. B. (1907). Exploraciones arqueológicas en la ciudad prehistórica de La Paya (Valle Calchaquí, provincia de Salta). Revista de la Universidad de Buenos Aires VIII, 1-534 (Publicaciones de la Sección Antropológica $\mathrm{N}^{\circ}$ 3, Facultad de Filosofía y Letras).

Arnheim, R. (1985). Arte y Percepción Visual. Sexta edición. Madrid: Alianza Editorial.

Aschero, C. A. (1988). Pinturas rupestres, actividades y recursos naturales: un encuadre arqueológico. En Yacobaccio, H. D. (Ed.). Arqueología Contemporánea Argentina, Actualidad y Perspectivas (pp. 109-145). Buenos Aires: Ediciones Búsqueda.

Aschero, C. A. (2000). Figuras humanas, camélidos y espacios en la interacción circumpuneña. En Podestá, M. M. y De Hoyos, M. (Eds.). Arte en las Rocas. Arte Rupestre, Menhires y Piedras de Colores en Argentina (pp. 15-44). Buenos Aires: Sociedad Argentina de Antropología.

Ávila, L. J., Martínez, L. E. y Morando, M. (2013). Checklist of lizards and amphisbaenians of Argentina: an update. Zootaxa, 3616(3), 201-238.

Balme, J. y Paterson, A. (Eds.). (2006). Archaeology in Practice. A Student Guide to Archaeological Analyses. India: Blackwell Publishing.
Banning, E. B. (2000). The Archaeologist's Laboratory. The Analysis of Archaeological Data. New York: Klumer Academic.

Basile, M. V. (2005 Ms.). Iconografía funeraria Belén en el Valle de Abaucán (Dpto. Tinogasta, Catamarca). Aportes para la definición de un estilo decorativo. Tesis de Licenciatura, Facultad de Filosofía y Letras, Universidad de Buenos Aires.

Basile, M. y Buono, H. (2013). Diseño de base de datos para el análisis de representaciones plásticas en soporte rupestre y cerámico. Cuadernos de Antropología, 9, 155-172.

Bedano, M. C., Juez, M. S. y Roca, M. D. (1993). Análisis del Material Arqueológico de la Colección Rosso Procedente del Departamento de Ambato, Provincia de Catamarca. Serie Tesis y Monografías $\mathrm{N}^{\circ} 1$, Publicaciones del Instituto de Arqueología 7, Universidad Nacional de Tucumán, San Miguel de Tucumán.

Bruch, C. (1911). Exploraciones Arqueológicas en las Provincias de Tucumán y Catamarca. Tomo V, Biblioteca Centenaria, Universidad Nacional de la Plata. Buenos Aires: Imprenta de Coni Hermanos.

Conkey, M. y Hastorf, C. (1990). Introduction. En Conkey, M. y Hastorf, C. (Eds.). The Uses of Style in Archaeology (pp. 1-4). Cambridge: Cambridge University Press.

De la Fuente, N. R., Nazar, D. C. y Pelli, E. H. (2005). Documentación y diagnóstico del arte rupestre de La Tunita, provincia de Catamarca, República Argentina. En La Cultura de La Aguada y sus Expresiones Regionales (pp. 227-244). Trabajos presentados en la V Mesa Redonda "La cultura de La Aguada y su dispersión". Museo de Ciencias Naturales, Secretaría de Ciencia y Tecnología, Universidad Nacional de La Rioja.

Fagan, B. M. (2003). Archaeology. A Brief Introduction. Octava edición. Upper Saddle River: Prentice Hall.

Falchi, M. P. y Podestá, M. M. (2015). "Aquí estuvimos, por acá pasamos". Grabados de pisadas y huellas humanas en los desiertos sur andinos. Arkeos, 37, 289-312. XIX International Rock Art Conference IFRAO 2015. En Collado Giraldo, H. y García Arranz, J. J. (Eds.). Symbols in the Landscape: Rock Art and its Context. Publicado en CD-Rom. 
Falchi, M. P., Podestá, M. M., Rolandi, D. S., Re, A. y Torres, M. A. (2011). Arte rupestre entre las sierras y los llanos riojanos: localidad arqueológica Palancho. Comechingonia. Revista de Arqueología, 15, 39-63.

Falchi, M. P., Podestá, M. M., Rolandi, D. S. y Torres, M. A. (2013). Grabados rupestres en el desierto rojo, Los Colorados (La Rioja, Argentina). Mundo de Antes, 8, 105-130.

Fernández Distel, A. A. (1983-84). Arqueología del oriente del departamento de Humahuaca: alero rocoso y fortaleza de Cianzo (provincia de Jujuy, Argentina). Empúries, 45-46, 30-41.

Fiadone, A. E. (2001). El Diseño Indígena Argentino. Una Aproximación a la Iconografía Precolombina. Buenos Aires: La Marca Editora.

Ford, J. A. (1954). The type concept revisited. American Anthropologist, 56(1), 42-54.

Garín, C. F. y Hussein, Y. (2013). Guía de Reconocimiento de Anfibios y Reptiles de la Región de Valparaiso. Valparaíso: Servicio Agrícola y Ganadero, Ministerio de Agricultura.

González, A. R. (1977). Arte Precolombino de la Argentina. Buenos Aires: Filmediciones Valero.

González, A. R. (1992). Las Placas Metálicas de los Andes del Sur. Contribución al Estudio de las Religiones Precolombinas. Mainz am Rhein: KAVA Band 46, Verlag Philipp Von Zabern.

Gordillo, I., Baldini, M. y Kusch, M. F. (2000). Entre objetos, rocas y cuevas: significados y relaciones entre la iconografía rupestre y mobiliar de Aguada. En Podestá, M. M. y De Hoyos, M. (Eds.). Arte en las Rocas. Arte Rupestre, Menhires y Piedras de Colores en Argentina (pp. 101-111). Buenos Aires: Sociedad Argentina de Antropología.

Goretti, M. (2006). Tesoros Precolombinos del Noroeste Argentino. Buenos Aires: Fundación Centro de Estudios para Políticas Públicas Aplicadas (CEPPA).

Goretti, M. (2007). Antes de América. Símbolos de Culto y Poder en las Culturas Prehispánicas. Buenos Aires: Fundación Centro de Estudios para Políticas Públicas Aplicadas (CEPPA).
Kligmann, D. M. (2009). Procesos de Formación de Sitios Arqueológicos: Tres Casos de Estudio en la Puna Meridional Catamarqueña Argentina. Oxford: Archaeopress - British Archaeological Reports (BAR) International Series 1949.

Kligmann, D. M. (2015). Archaeological applications of microvertebrate analysis: reconstruction of natural and anthropic processes. Archaeofauna. International Journal of Archaeozoology, 24, 315-339.

Kligmann, D. M. y Albino, A. M. (2007). Análisis de los restos óseos de reptiles hallados en una vasija cerámica, Tolombón, Salta. Resúmenes Ampliados del XVI Congreso Nacional de Arqueología Argentina, tomo I, 479-481.

Kligmann, D. M., Albino, A. M. y Díaz País, E. (2013). Anfisbenas para los dioses: Zooarqueología de una ofrenda animal. En Izeta, A. D. y Mengoni Goñalons, G. L. (Eds.). De la Puna a las Sierras: Avances y Perspectivas en Zooarqueología Andina (pp. 89-120). Oxford: South American Archaeology Series 19, British Archaeological Reports (BAR) International Series 2564, John \& Erica Hedges, Ltd.

Kligmann, D. M. y Díaz País, E. (2007). Una primera aproximación a los motivos serpentiformes de la iconografía Aguada del NOA. Intersecciones en Antropología, 8, 49-67.

Kligmann, D. M. y Falchi, M. P. (2016 Ms.). La imagen de la lagartija en la iconografía prehispánica del Noroeste Argentino: una propuesta tipológica. Trabajo presentado en el Simposio: De la imagen a los contextos. Sobre las maneras de abordar e interpretar la producción visual en Arqueologí, XIX Congreso Nacional de Arqueología Argentina, San Miguel de Tucumán.

Kligmann, D. M. y Falchi, M. P. (2017 Ms.). La imagen de la lagartija en la iconografía prehispánica del Noroeste Argentino II: análisis tipológico de su representación.

Kligmann, D. M., Sesé, C. y Barbadillo, J. (1999). Análisis tafonómico de la fauna de microvertebrados del Alero 12 (Puna meridional catamarqueña argentina) y sus implicancias para el comportamiento humano. Arqueología, 9, $9-48$.

Kusch, M. F. (1991). Forma, diseño y figuración en la cerámica pintada y grabada de La Aguada. En Podestá, 
M. M., Hernández Llosas, M. I. y Renard de Coquet, S. F. (Eds.). El Arte Rupestre en la Arqueología Contemporánea (pp. 14-24). Buenos Aires: Salón Gráfico Integral S.R.L.

Lafone Quevedo, S. A. (1908). Tipos de Alfarería en la Región Diaguito-Calchaqui. Universidad Nacional de La Plata. Buenos Aires: Imprenta de Coni Hermanos.

Montenegro, M. y Ruiz, M. (2004). Hacia un análisis de imágenes visuales: la iconografía como herramienta metodológica en Arqueología. En Austral, A. y Tamagnini, M. (Comps.). Problemáticas de la Arqueología Contemporánea, Tomo III (pp. 829-845). Río Cuarto: Facultad de Ciencias Humanas, Facultad de Ciencias Exactas, Físico-Químicas y Naturales, Universidad Nacional de Río Cuarto. Argentina.

Muzzolini, A. (1995). Arte Rupestre del Sahara. Pinerolo: Centro di Studi e Museo d'Arte Preistórica.

Núñez, L. y Castro, V. (2011). ¡Caiatunar, caiatunar! Pervivencia de ritos de fertilidad prehispánica en la clandestinidad del Loa (norte de Chile). Estudios Atacameños. Arqueología y Antropología Surandinas, 42, 153-172.

Palermo, M. A. (Ed.). (1984a). Lagartijas y Otros Saurios I. Buenos Aires: Fauna Argentina 91, Centro Editor de América Latina.

Palermo, M. A. (Ed.) (1984b). Lagartijas y Otros Saurios II. Buenos Aires: Fauna Argentina 92, Centro Editor de América Latina.

Panofsky, E. (1988). Estudios sobre Iconología. Madrid: Alianza Editorial.

Podestá, M. M. y Falchi, M. P. (2015). Suris, camélidos, felinos y otras huellas. Simbología y contexto arqueológico en el arte rupestre sur andino. Arkeos 37: 2191-2218. XIX International Rock Art Conference IFRAO 2015. En Collado Giraldo, H. y García Arranz, J. J. (Eds.). Symbols in the Landscape: Rock Art and its Context. Publicado en CD-Rom.

Podestá, M. M., Ré, A. y Romero Villanueva, G. (2001). Visibilizando lo invisible. Grabados históricos como marcadores idiosincráticos en Ischigualasto (San Juan, Argentina). En Núńez, L. y Nielsen A. E. (Eds.). En Ruta. Arqueología, Historia y Etnografía del Tráfico Sur
Andino (pp. 341-372). Córdoba: Encuentro Grupo Editor.

Renfrew, C. y Bahn, P. (1991). Archaeology. Theories, Methods and Practice. New York: Thames and Hudson.

Rice, P. C. (1997). Doing Archaeology: a Hands-On Laboratory Manual. Mountain View: Mayfield Publishing Company.

Romero, G. (2016). La clasificación de las pinturas rupestres del noreste del Neuquén, Patagonia septentrional. En Oliva, F., Roccchietti, A. M. y Solomita Banfi, F. (Eds.). Imágenes Rupestres: Lugares y Regiones (441-452). Rosario: Facultad de Humanidades y Artes, Universidad Nacional de Rosario. Argentina.

Schobinger, J. y Gradin, C. J. (1985). Arte Rupestre de la Argentina. Cazadores de la Patagonia y Agricultores Andinos. Madrid: Ediciones Encuentro.

Sempé, M. C. (1998). Contacto cultural en el sitio Aguada Orilla Norte. En Homenaje a Alberto Rex González. 50 Años de Aportes al Desarrollo y Consolidación de la Antropología Argentina (pp. 255-283). Buenos Aires: Fundación Argentina de Antropología y Facultad de Filosofía y Letras, Universidad de Buenos Aires.

Sempé, M. C. y Baldini, M. I. (2002). Contextos temáticos y ordenamientos funerarios en el cementerio Aguada Orilla Norte. Relaciones de la Sociedad Argentina de Antropologia, XXVII, 247-269.

Sempé, M. C. y Baldini, M. I. (2004). Contextos temáticos funerarios de las tumbas Aguada gris grabado del cementerio Aguada Orilla Norte, Catamarca. Relaciones de la Sociedad Argentina de Antropología, XXIX, 275-295.

Serrano, A. (1966). Manual de la Cerámica Indigena. Segunda edición. Córdoba: Editorial Assandri.

Sharer, R. J. y Ashmore, W. (1987). Archaeology. Discovering our Past. Mountain View: Mayfield Publishing Company.

Spaulding, A. C. (1953). Statistical techniques for the discovery of artifact types. American Antiquity, 18(4), 305-313.

Staeck, J. P. (2002). Back to the Earth. An Introduction to Archaeology. Mountain View: Mayfield Publishing Company. 
Thomas, D. H. (1979). Archaeology. New York: Holt, Rinehart and Winston.

Thomas, D. H. y Kelly, R. L. (2006). Archaeology. Cuarta edición. Belmont: Thompson - Wadsworth.

Troncoso, A. (2003). Proposición de estilos para el arte rupestre del valle de Putaendo, curso superior del río Aconcagua. Chungara. Revista de Antropología Chilena, 35(2), 209-231.
Troncoso, A. y Jackson, D. (2010). Images that travel: Aguada rock art in north-central Chile. Rock Art Research, 27(1), 43-60.

Valenzuela, D., Sepúlveda, M., Santoro, C. y Montt, I. (2014). Arte rupestre, estilo y cronología: La necesidad de un contexto histórico para las manifestaciones rupestres en costa y valles del extremo norte de Chile. Interciencia, 39(7), 444-449. 